\title{
Application of Physiologically Based Pharmacokinetic Modeling in Understanding Bosutinib Drug-Drug Interactions: Importance of Intestinal P-Glycoprotein ${ }^{\llbracket}$
}

\author{
Shinji Yamazaki, Cho-Ming Loi, Emi Kimoto, Chester Costales, and Manthena V. Varma
}

Pharmacokinetics, Dynamics and Metabolism, Pfizer Worldwide Research \& Development, San Diego, California (S.Y., C.-M.L.) and Groton, Connecticut (E.K., C.C., M.V.V.)

Received January 8, 2018; accepted May 7, 2018

\begin{abstract}
Bosutinib is an orally available Src/Abl tyrosine kinase inhibitor indicated for the treatment of patients with $\mathrm{Ph}+$ chronic myelogenous leukemia at a clinically recommended dose of $500 \mathrm{mg}$ once daily. Clinical results indicated that increases in bosutinib oral exposures were supraproportional at the lower doses (50-200 mg) and approximately dose-proportional at the higher doses (200$600 \mathrm{mg}$ ). Bosutinib is a substrate of CYP3A4 and P-glycoprotein and exhibits $\mathrm{pH}$-dependent solubility with moderate intestinal permeability. These findings led us to investigate the factors influencing the underlying pharmacokinetic mechanisms of bosutinib with physiologically based pharmacokinetic (PBPK) models. Our primary objectives were to: 1 ) refine the previously developed bosutinib PBPK model on the basis of the latest oral bioavailability data and 2) verify the refined PBPK model with P-glycoprotein kinetics on the basis of the bosutinib drug-drug interaction (DDI)
\end{abstract}

results with ketoconazole and rifampin. Additionally, the verified PBPK model was applied to predict bosutinib DDls with dual CYP3A/P-glycoprotein inhibitors. The results indicated that 1) the refined PBPK model adequately described the observed plasma concentration-time profiles of bosutinib and 2) the verified PBPK model reasonably predicted the effects of ketoconazole and rifampin on bosutinib exposures by accounting for intestinal P-glycoprotein inhibition/induction. These results suggested that bosutinib DDI mechanism could involve not only CYP3A4-mediated metabolism but also P-glycoprotein-mediated efflux on absorption. In summary, P-glycoprotein kinetics could constitute an element in the PBPK models critical to understanding the pharmacokinetic mechanism of dual CYP3A/P-glycoprotein substrates, such as bosutinib, that exhibit nonlinear pharmacokinetics owing largely to a saturation of intestinal P-glycoprotein-mediated efflux.

\section{Introduction}

For predicting and understanding pharmacokinetics, drug-drug interactions (DDIs), drug-disease interactions, and pediatric/geriatric therapies of new molecular entities (NMEs), mechanistic modeling and simulation approaches are being applied increasingly to all phases of drug discovery and development, as well as to regulatory decisions on labeling languages (Rowland et al., 2011; Huang and Rowland, 2012; Wagner et al., 2015, 2016; Shebley et al., 2018). Among the modeling and simulation approaches, a physiologically based pharmacokinetic (PBPK) model is a powerful tool to quantitatively predict DDIs on the basis of drug-dependent physicochemical and pharmacokinetic parameters along with drug-independent physiological systems parameters (Lave et al., 2007; Nestorov, 2007; Rowland et al., 2011; Jones and Rowland-Yeo, 2013; Jones et al., 2015). Recently, the US Food and Drug Administration (FDA), the European Medicines Agency (EMA), and the Japanese Pharmaceuticals and Medical Devices Agency

This study was sponsored by Pfizer, Inc.

https://doi.org/10.1124/dmd.118.080424.

S This article has supplemental material available at dmd.aspetjournals.org.
(PMDA) have issued DDI guidances, which highlight the use of integrated mechanistic approaches, including PBPK models: (http:// www.ema.europa.eu/docs/en_GB/document_library/Scientific_guideline/ 2012/07/WC500129606.pdf; http://www.nihs.go.jp/mss/T140710-jimu.pdf; https://www.fda.gov/downloads/drugs/guidancecomplianceregulatory information/guidances/ucm292362.pdf; https://www.fda.gov/downloads/ Drugs/GuidanceComplianceRegulatoryInformation/Guidances/ UCM581965.pdf). Accordingly, there has been a growing emphasis in developing PBPK models to assess potential DDI risks of NMEs in a drug discovery and development setting.

Bosutinib (Bosulif), an orally available Src/Abl tyrosine kinase inhibitor, has been approved globally for the treatment of adult patients with chronic, accelerated, or blast phase $\mathrm{Ph}+$ chronic myelogenous leukemia with resistance or intolerance to prior therapy (http://www. accessdata.fda.gov/drugsatfda_docs/label/2016/203341s006lbl.pdf). Clinically recommended dose of bosutinib is $500 \mathrm{mg}$ once daily under fed conditions. Bosutinib is a substrate of CYP3A4 and P-glycoprotein (P-gp) and exhibits $\mathrm{pH}$-dependent aqueous solubility over the $\mathrm{pH}$ range of 1-8 with moderate in vitro passive permeability (http://www.accessdata.fda.gov/ drugsatfda_docs/nda/2012/203341Orig1s000ClinPharmR.pdf). In phase I

ABBREVIATIONS: ADAM, advanced dissolution, absorption, and metabolism; AUC, area under the plasma concentration-time curve; AUCR, AUC ratio; $\mathrm{CL}_{\text {int }}$, intrinsic clearance; $\mathrm{C}_{\max }$, maximum plasma concentration; $\mathrm{C}_{\max } R, \mathrm{C}_{\max }$ ratio; $\mathrm{DDI}$, drug-drug interaction; $F_{a}$, fraction of the dose absorbed from gastrointestinal tract; $F_{g}$, fraction of the dose that escapes intestinal first-pass metabolism; $F_{h}$, fraction of the dose that escapes hepatic first-pass metabolism; $f_{u}$, unbound fraction; NME, new molecular entity; PBPK, physiologically-based pharmacokinetic(s); P-gp, Pglycoprotein; $\mathrm{P} / \mathrm{O}$, predicted-to-observed pharmacokinetic parameters; $\mathrm{SAO}$, sensitivity analysis and optimization; $\mathrm{SF}$, scaling factor; $\mathrm{t}_{\mathrm{max}}$, time to reach maximum plasma concentration; $V_{s s}$, volume of distribution at steady-state. 
studies, increases in bosutinib exposures, estimated as maximum plasma concentration $\left(\mathrm{C}_{\max }\right)$ and area under the plasma concentration-time curve (AUC), were supraproportional at doses of 50-200 mg and approximately dose-proportional at doses of 200-600 mg (http://www.accessdata.fda.gov/ drugsatfda_docs/nda/2012/203341Orig1s000ClinPharmR.pdf). In contrast, bosutinib terminal half-lives were comparable between these doses (i.e., 13-22 hours). Since bosutinib is a substrate of P-gp, the nonlinear-to-linear pharmacokinetic profiles from lower to higher doses could be considered owing mainly to a saturation of intestinal P-gp-mediated efflux on absorption, resulting in dose-dependent increases in a fraction of the dose absorbed from the gastrointestinal tract $\left(\mathrm{F}_{\mathrm{a}}\right)$. These findings led us to investigate the factors influencing the underlying pharmacokinetic mechanisms with PBPK models.

Bosutinib is predominantly metabolized by CYP3A4 as the primary clearance mechanism in humans with minimal urinary excretion ( $<2 \%$ of the administered dose) (http://www.accessdata.fda.gov/ drugsatfda_docs/nda/2012/203341Orig1s000ClinPharmR.pdf; Syed et al., 2014). For the potential DDI risk assessment as the CYP3A4 substrate, bosutinib single-dose DDI studies were conducted in healthy volunteers with coadministration of a strong CYP3A inhibitor, ketoconazole (400 mg once daily), and a strong CYP3A inducer, rifampin (600 mg once daily) (Abbas et al., 2011, 2012, 2015). Bosutinib exposures estimated as $\mathrm{C}_{\max }$ and AUC increased by up to 9-fold when coadministered with ketoconazole, and decreased by $\sim 90 \%$ when coadministered with rifampin. Accordingly, the US prescribing information advises avoidance of concurrent use of bosutinib with strong or moderate CYP3A inhibitors and inducers (http://www.accessdata.fda.gov/drugsatfda_docs/label/2016/ 203341s006lbl.pdf). A postmarketing requirement by FDA was issued to evaluate the effect of moderate CYP3A4 inhibitors on bosutinib exposures to identify an appropriate dose when used concomitantly with moderate CYP3A inhibitors (http://www.accessdata.fda.gov/drugsatfda_docs/ nda/2012/203341Orig1s000ClinPharmR.pdf). Accordingly, we developed bosutinib PBPK models to predict clinical DDIs with less potent CYP3A inhibitors (Ono et al., 2017). The model-predicted results (2- to 4-fold) with several moderate CYP3A inhibitors were consistent with the observed results $(\sim 2$-fold) with a moderate CYP3A inhibitor, aprepitant (125 mg) (Hsyu et al., 2017). We also applied the PBPK models to predict changes in bosutinib steady-state exposures in patients with renal and hepatic impairment (Ono et al., 2017).

It has become a common practice to verify PBPK models of NMEs and refine the models, if necessary, when new datasets are available during drug development. Recently, an absolute oral bioavailability $\left(\mathrm{F}_{\text {oral }}\right)$ study of bosutinib was conducted in healthy subjects following an intravenous 1-hour infusion of $120 \mathrm{mg}$ and an oral dose of $500 \mathrm{mg}$ (Hsyu et al., 2018). However, the predicted bosutinib exposures by the previously developed PBPK model could not sufficiently match the results observed in the $F_{\text {oral }}$ study, indicating that a further refinement of bosutinib PBPK model was required to adequately describe clinically observed results. Accordingly, we refined the previously developed bosutinib PBPK model on the basis of the latest $F_{\text {oral }}$ data and verified the refined PBPK model with P-glycoprotein kinetics on the basis of single-dose bosutinib DDI results. In addition, the verified PBPK model was applied to predict bosutinib DDIs under clinical scenarios that have not been tested. In these modeling processes, we focused on 1) understanding the contribution of intestinal P-gp-mediated efflux to bosutinib pharmacokinetics and 2) quantitatively rationalizing bosutinib DDI mechanism by ketoconazole and rifampin.

\section{Materials and Methods}

\section{Bosutinib Pharmacokinetic Studies in the Clinic}

Detailed information from bosutinib clinical studies, such as a single-dose $\mathrm{F}_{\text {oral }}$ study in healthy volunteers and single-dose DDI studies with ketoconazole and rifampin in healthy volunteers, have been reported previously (Abbas et al., 2010, 2011, 2012; Hsyu et al., 2018) Additional information about bosutinib pharmacokinetics is also available in the FDA website (http://www.accessdata. fda.gov/drugsatfda_docs/nda/2012/203341Orig1s000ClinPharmR.pdf). Briefly, the $\mathrm{F}_{\text {oral }}$ study of bosutinib was conducted as a two-way crossover design in healthy male subjects $(n=13-14)$ under fed conditions (Hsyu et al., 2018). A single dose of bosutinib was administered to subjects either intravenously $(120 \mathrm{mg}$ in a 1-hour infusion) or orally $(500 \mathrm{mg} ; 100-\mathrm{mg}$ tablet $\times 5)$, and plasma concentrations of bosutinib were determined up to 7 days postdose. For the bosutinib DDI assessment, three single-dose studies were conducted in healthy male and female subjects with multiple-dose coadministration of ketoconazole (two studies at bosutinib doses of 100 and $500 \mathrm{mg}$ ) and rifampin (one study at bosutinib dose of $500 \mathrm{mg}$ ) (Abbas et al., 2011, 2012, 2015). In the bosutinib 100 -mg DDI study with ketoconazole, each subject $(n=24)$ received a single oral dose of $100 \mathrm{mg}$ bosutinib (day 1) in a fasted state either alone (control group) or with 5-day repeated oral doses of $400 \mathrm{mg}$ ketoconazole once daily on days $0-4$ (treatment group). In the bosutinib 500-mg DDI study with ketoconazole, each subject ( $n=54-56$ ) received a single oral dose of $500 \mathrm{mg}$ bosutinib (day 1 ) in a fed state either alone (control group) or with 4-day repeated oral doses of $400 \mathrm{mg}$ ketoconazole once daily on days $0-4$ (treatment group). In the bosutinib 500-mg DDI study with rifampin, each subject $(n=22-24)$ received a single oral dose of $500 \mathrm{mg}$ bosutinib (days 1 and 14) in a fed state with 10-day repeated oral doses of $600 \mathrm{mg}$ rifampin once daily (days 8-17). Plasma concentrations of bosutinib in all subjects were determined up to 72 or 96 hours postdose in these DDI studies.

\section{Bosutinib Input Parameters in the PBPK Model}

A commercially available dynamic PBPK model, Simcyp population-based simulator (version 17.1; Simcyp Ltd., Sheffield, United Kingdom), was used in the present study (Jamei et al., 2009a). First, the previously developed PBPK model was refined on the basis of the latest $F_{\text {oral }}$ results as mentioned before. The main differences in bosutinib input parameters between the previous and present PBPK models were hepatic microsomal intrinsic clearance $\left(\mathrm{CL}_{\mathrm{int}}\right)$ and steadystate volume of distribution $\left(\mathrm{V}_{\mathrm{ss}}\right)$. In addition, we used the advanced dissolution, absorption, and metabolism (ADAM) model implemented in Simcyp to incorporate intestinal P-gp kinetic parameters into the present PBPK model. In the ADAM model, the gastrointestinal tract is divided into nine different regions, namely stomach, duodenum, jejunum I and II, ileum I, II, III and IV, and colon, as subcompartments. Physicochemical and pharmacokinetic parameters of bosutinib used for the present PBPK models are summarized in Table 1.

Input Parameters for CL. The value of $\mathrm{CL}_{\text {int }}(560 \mu \mathrm{l} / \mathrm{min}$ per milligram protein) in the present model was back-calculated from an intravenous plasma clearance $(\sim 62 \mathrm{l} / \mathrm{h})$ estimated in the $\mathrm{F}_{\text {oral }}$ study using a retrograde model implemented in Simcyp, whereas that (300 $\mu \mathrm{l} / \mathrm{min}$ per milligram protein) in the previous model was estimated from a clinically observed oral clearance $(\sim 200$ 1/h) (Ono et al., 2017). Thus, a fraction of the dose that escapes hepatic first-pass metabolism $\left(\mathrm{F}_{\mathrm{h}}\right)$ was estimated to be approximately $\sim 0.5$ on the basis of the intravenous blood clearance $(\sim 0.74 \mathrm{l} / \mathrm{h}$ per kilogram) given that the primary clearance mechanism was CYP3A4-mediated hepatic metabolism. Since a fraction of the dose metabolized by CYP3A4 $\left(f_{m, C Y P 3 A 4}\right)$ was estimated as near-unity on the basis of the in vitro cytochrome $\mathrm{P} 450$ phenotyping and the human mass-balance study, the back-calculated $\mathrm{CL}_{\text {int }}$ values were subsequently assigned as CYP3A4-mediated metabolic $\mathrm{CL}_{\text {int }}$ in human liver microsomes in PBPK models. The input value of $\mathrm{CL}_{\text {int }}$ in human liver microsomes was scaled to CYP3A4-mediated intestinal clearance by accounting for CYP3A4 abundance in liver and intestine. Bosutinib renal clearance $\left(\mathrm{CL}_{\text {renal }}\right)$ was set at $1.21 / \mathrm{h}(\sim 2 \%$ of systemic clearance) on the basis of the mass-balance results.

Input Parameters for $\mathbf{V}_{\mathbf{s s}}$. The $\mathrm{V}_{\mathrm{ss}}$ input $(28 \mathrm{l} / \mathrm{kg})$ in the present PBPK model was a clinical estimate in the $F_{\text {oral }}$ study, whereas that in the previous model $\left(15 \mathrm{l} / \mathrm{kg}\right.$ ) was a mean value of the predicted human $\mathrm{V}_{\mathrm{ss}}$ from single-species scaling for unbound $\mathrm{V}_{\mathrm{ss}}$ values from mice, rats, and dogs $(12-21 \mathrm{l} / \mathrm{kg})$ with an exponent of unity (Ono et al., 2017). The predicted $\mathrm{V}_{\mathrm{ss}}$ value by the tissue composition-based mathematical model implemented in Simcyp (as prediction method 2) was 7.5 $1 / \mathrm{kg}$ (Rodgers et al., 2005); therefore, $\mathrm{K}_{\mathrm{p}}$ scalars of 2.0 and 3.7 were used to set $\mathrm{V}_{\mathrm{ss}}$ inputs of 15 and $28 \mathrm{l} / \mathrm{kg}$, respectively.

Absorption Models. A fraction of the dose absorbed $\left(\mathrm{F}_{\mathrm{a}}\right)$ was estimated at approximately 0.7 in a single-dose human mass-balance study with $\left[{ }^{14} \mathrm{C}\right]$ bosutinib at a dose of $500 \mathrm{mg}$ since the recovery of bosutinib (as the parent drug) in feces was $30 \%$ of the administered dose and the fecal recovery of bosutinib was unlikely 
TABLE 1

Physicochemical and pharmacokinetic parameters of bosutinib used for PBPK models

\begin{tabular}{|c|c|c|}
\hline Parameter (U) & Value & Source \\
\hline Molecular weight & 530 & Calculated \\
\hline $\log P$ & 3.1 & Measured \\
\hline $\mathrm{pK}_{\mathrm{a}}$ (monobase) & 7.9 & Measured \\
\hline $\mathrm{f}_{\mathrm{u} \text {,plasma }}$ & 0.063 & Measured in vitro \\
\hline $\mathrm{B} / \mathrm{P}$ & 1.2 & Measured in vitro \\
\hline $\mathrm{F}_{\mathrm{a}}^{a}$ & $0.3-0.7$ & Mass-balance study results \\
\hline $\mathrm{k}_{\mathrm{a}}\left(\mathrm{h}^{-1}\right)^{a}$ & 0.13 & Clinical study results \\
\hline Lag time $(\mathrm{h})^{a}$ & 1 & Clinical study results \\
\hline Solubility $(\mathrm{mg} / \mathrm{ml})$ & $0.02-11$ (at $\mathrm{pH} 1-8)$ & Measured in vitro \\
\hline$P_{\text {eff,man }}\left(10^{-4} \mathrm{~cm} / \mathrm{s}\right)$ & 1.8 & Calculated from in vitro data \\
\hline $\mathrm{Q}_{\text {gut }}(1 / \mathrm{h})^{a}$ & 8.7 & Calculated by Simcyp \\
\hline$f_{u, \text { gut }}$ & 0.063 & Predicted by sensitivity analysis \\
\hline $\mathrm{V}_{\mathrm{ss}}(1 / \mathrm{kg})$ & 28 & Clinical study results \\
\hline $\mathrm{K}_{\mathrm{p}}$ scalar & 3.7 & Adjusted to predict the observed $\mathrm{V}_{\mathrm{ss}}$ value \\
\hline $\mathrm{CL}_{\text {int,CYP3A4 }}(\mu \mathrm{l} / \mathrm{min} \text { per milligram protein })^{b}$ & 560 & Back-calculated in Simcyp \\
\hline $\mathrm{CL}_{\text {renal }}(\mathrm{l} / \mathrm{h})$ & 1.2 & Clinical study results \\
\hline P-gp $\mathrm{K}_{\mathrm{m}}(\mu \mathrm{M})^{c}$ & 0.38 & Measured in Caco- 2 cells \\
\hline $\mathrm{P}$-gp $\mathrm{J}_{\max }(\mathrm{pmol} / \mathrm{min})^{c}$ & 15 & Measured in Caco- 2 cells \\
\hline $\mathrm{P}$-gp $\mathrm{J}_{\max } \mathrm{SF}^{c}$ & $1-25$ & Optimized to recover the observed results \\
\hline
\end{tabular}

${ }^{a}$ Input parameters used for PBPK- $\mathrm{F}_{\mathrm{a}}$ models.

${ }^{b}$ Human liver microsomal $C L_{\text {int }}$ back-calculated from the clinically observed clearance $(\sim 62 \mathrm{l} / \mathrm{h})$ using a retrograde model.

${ }^{c}$ Intestinal P-pg parameters used for PBPK-ADAM models.

confounded by biliary excretion of the unchanged drug and/or reversible metabolites on the basis of the metabolic profiling results in the clinical studies, including a mass-balance study (Abbas et al., 2010; http://www.accessdata.fda.gov/ drugsatfda_docs/nda/2012/203341Orig1s000ClinPharmR.pdf; Ono et al., 2017). Therefore, bosutinib $\mathrm{F}_{\mathrm{a}}$ was set at 0.7 at a dose of $500 \mathrm{mg}$ in the PBPK models with the first-order absorption rate constants (henceforth referred to as PBPK- $F_{a}$ models). Furthermore, the ADAM model was used to incorporate intestinal P-gp kinetics into bosutinib absorption (henceforth referred to as PBPK-ADAM models). It may be worth noting that P-gp kinetics can be incorporated only into the PBPK-ADAM models in Simcyp (Jamei et al., 2009b). The regional distribution of P-gp abundance along with cytochrome 450 enzymes in intestine and its variability derived from meta-analysis of reported protein and mRNA values are incorporated into the population library of Simcyp (e.g., a virtual population of healthy volunteers). To predict bosutinib $F_{a}$, the ADAM models integrate the physicochemical and biopharmaceutical properties of bosutinib such as $\mathrm{pH}$-dependent solubility $(11,9.4$, $6.1,2.7,0.02$, and $0.053 \mathrm{mg} / \mathrm{ml}$ at $\mathrm{pH} 1,2,4.5,5,6.8$, and 8 , respectively) and the intestinal effective permeability $\left(1.8 \times 10^{-4} \mathrm{~cm} / \mathrm{s}\right)$ calculated from in vitro passive permeability $\left(\sim 7 \times 10^{-6} \mathrm{~cm} / \mathrm{s}\right)$ in low-efflux Madin-Darby canine kidney cells (Di et al., 2011; http://www.accessdata.fda.gov/drugsatfda_docs/nda/2012/ 203341Orig1s000ClinPharmR.pdf). In addition, the disintegration profile was defined in the ADAM models by the first-order kinetics with $100 \%$ maximal disintegration, a disintegration constant of 0.01 hour $^{-1}$ and a lag time of 0.25 hours. Bosutinib in vitro P-gp kinetics were determined in the Caco-2 permeability study at the concentrations of $1-100 \mu \mathrm{M}$ (http://www.accessdata. fda.gov/drugsatfda_docs/nda/2012/203341Orig1s000ClinPharmR.pdf). The estimated $\mathrm{K}_{\mathrm{m}}$ (concentration required to achieve half of the maximal transport rate) and $\mathrm{J}_{\max }$ (maximal transport rate) were $3.8 \mu \mathrm{M}$ and $15 \mathrm{pmol} / \mathrm{min}$, respectively, on the basis of the kinetic model (Tachibana et al., 2010). This model assumes steadystate condition to calculate kinetic parameters; therefore, the obtained $K_{m}$ value was corrected for in vitro non-specific binding $(\sim 0.1)$ as an extracellular nonspecific binding, resulting in the unbound $\mathrm{K}_{\mathrm{m}}$ of $0.38 \mu \mathrm{M}$ as an input parameter. These calculations were performed with GraphPad Prism 6 (GraphPad Software Inc., San Diego, CA). In the PBPK-ADAM models, an in vitro-to-in vivo scaling factor (SF) for P-gp $J_{\max }$ was optimized to adequately recover the observed results, whereas $K_{m}$ was assumed to be intrinsic and was fixed.

\section{PBPK Simulation by Simcyp}

To understand bosutinib pharmacokinetics, our modeling and simulation approaches are practically categorized into three main tiers: 1 ) model refinement on the basis of the latest $\mathrm{F}_{\text {oral }}$ data, 2) model verification on the basis of the singledose bosutinib DDI results, and 3) model application to predict bosutinib DDIs under possible scenarios that have not been tested clinically. In these processes, sensitivity analysis and optimization (SAO) for the model input parameters such as unbound fraction $\left(\mathrm{f}_{\mathrm{u}}\right)$ in gut $\left(\mathrm{f}_{\mathrm{u}, \mathrm{gut}}\right)$ and SFs for P-gp $\mathrm{J}_{\text {max }}$ were performed as the model refinement and verification. Outlines of the PBPK modeling and simulation are summarized in Table 2 along with key parameters explored.

Simulation Outlines. Simulation of all clinical trials in Simcyp was performed with a virtual population of healthy volunteers in six trials of six subjects (total 36 subjects), each aged 20-50 years with a female/male ratio of 0.5 , whose CYP3A4 degradation rate constant $\left(\mathrm{k}_{\mathrm{deg}}\right)$ was 0.0193 hour $^{-1}$ in liver and 0.03 hour $^{-1}$ in intestine. The output sampling interval in Simcyp simulation tool box was set to 0.2 hours in all simulations. In the PBPK-ADAM models, the gastric emptying time in virtual populations was modified from the default values of 0.4 hours in fasted and 1 hour in fed to the maximal values of 2 and 4 hours, respectively, to sufficiently adapt clinically observed time to reach maximum plasma concentration ( $\mathrm{t}_{\max } ; 4-6$ hours) (http://www.accessdata.fda.gov/drugsatfda_docs/nda/2012/203341Orig1s000ClinPharmR.pdf). It has been reported that the mean gastric emptying time was $15.3 \pm 4.7$ hours (4.3-20 hours) in healthy subjects $(n=19)$ following the standard high-fat meal recommended by the FDA guidance (Koziolek et al., 2015). In the $\mathrm{F}_{\text {oral }}$ and DDI studies, the study outlines of all simulation were on the basis of the clinical study designs described above. For model application, a single oral dose of bosutinib $500 \mathrm{mg}$ was administered to a virtual population of healthy volunteers on day 5 with and without 16-day repeated oral administration of dual CYP3A/P-glycoprotein inhibitors, itraconazole (200 mg once daily) and verapamil ( $80 \mathrm{mg}$ three times a day).

DDI Prediction on P-gp. Regarding DDIs on intestinal P-gp-mediated efflux, ketoconazole was assumed to inhibit P-gp-mediated efflux in a competitive manner. The reported ketoconazole in vitro $\mathrm{IC}_{50}$ values against $\mathrm{P}$-gp varied $\sim 200$ fold (a median of $2.0 \mu \mathrm{M}$ with a range of $0.24-49 \mu \mathrm{M}$ using various substrates) or $\sim 11$-fold (a median of $1.5 \mu \mathrm{M}$ with a range of $0.42-4.6 \mu \mathrm{M}$ using digoxin as a substrate) in the Metabolism and Transport Drug Interaction Database (DIDB; School of Pharmacy, University of Washington, Seattle, WA). Therefore, the SAO for ketoconazole inhibition constant $\left(\mathrm{K}_{\mathrm{i}}\right)$ were performed with PBPKADAM models to adequately recover clinical DDI results. Rifampin was assumed to increase intestinal P-gp abundances in PBPK-ADAM models since it was reported that multiple-dose administration of rifampin increased the intestinal P-gp abundances by 3.5-fold, similar to the 4.5-fold for intestinal CYP3A4 (Greiner et al., 1999). Another report also indicated that multiple-dose administration of rifampin increased intestinal P-gp expression (mRNA) and abundance (protein) by 3- and 8-fold, respectively (Giessmann et al., 2004). However, there is no function in Simcyp for precipitant drug-mediated increases in P-gp abundances. Therefore, SFs for P-gp $\mathrm{J}_{\max }$ were assumed to increase with increasing intestinal P-gp abundances by rifampin-mediated induction. This also assumed that increases in intestinal P-gp abundances were proportional to increases in P-gp-mediated efflux activities. Accordingly, the SAO for P-gp $\mathrm{J}_{\max }$ 
TABLE 2

Outlines of bosutinib PBPK modeling for model refinement, verification, and application

\begin{tabular}{|c|c|c|c|c|c|}
\hline PBPK Model ${ }^{a}$ & Approach & Bosutinib Dose (mg) & Precipitant Drug & Clinical Studies Used & Key Parameters Explored \\
\hline IV & Refinement & $120^{b}$ & - & $F_{\text {oral }}$ & $\mathrm{CL}_{\mathrm{int}}$ and $\mathrm{V}_{\mathrm{ss}}$ \\
\hline \multirow[t]{3}{*}{$\mathrm{F}_{\mathrm{a}}$} & Refinement & 500 & - & $\mathrm{F}_{\text {oral }}$ & $\mathrm{f}_{\mathrm{u}, \mathrm{gut}}$ \\
\hline & Verification & 100 and 500 & Ketoconazole & DDI & $\mathrm{C}_{\max } \mathrm{R}$ and AUCR \\
\hline & & 500 & Rifampin & DDI & $\mathrm{C}_{\max } \mathrm{R}$ and $\mathrm{AUCR}$ \\
\hline \multirow[t]{6}{*}{ ADAM } & Refinement & 500 & - & $\mathrm{F}_{\text {oral }}$ & P-gp kinetics $\left(\mathrm{J}_{\max } \mathrm{SF}\right)^{c}$ \\
\hline & & 100 and 500 & - & $\mathrm{DDI}^{d}$ & P-gp kinetics $\left(\mathrm{J}_{\max } \mathrm{SF}\right)^{c}$ \\
\hline & Verification & 100 and 500 & Ketoconazole & DDI & P-gp inhibition $\left(\mathrm{K}_{\mathrm{i}}\right)^{e}$ \\
\hline & & 500 & Rifampin & DDI & P-gp induction (abundance) \\
\hline & Application & 500 & Itraconazole & - & DDI prediction \\
\hline & & 500 & Verapamil & - & DDI prediction \\
\hline
\end{tabular}

- , not applicable.

${ }^{a}$ PBPK model without absorption model (PBPK-IV), PBPK model with the first order absorption model (PBPK-F $\mathrm{F}_{\mathrm{a}}$ ), and PBPK model with the ADAM model using P-gp kinetic parameters (PBPK-ADAM).

${ }^{b}$ Single intravenous 1 -hour infusion.

${ }^{c}$ In vitro-to-in vivo scaling factor (SF) for intestinal P-gp $\mathrm{J}_{\max }$.

${ }^{d}$ Control groups (bosutinib alone) of the DDI study with ketoconazole (100 and $500 \mathrm{mg}$ ) and rifampin (500 mg).

${ }^{e}$ Ketoconazole $\mathrm{K}_{\mathrm{i}}$ for intestinal P-gp.

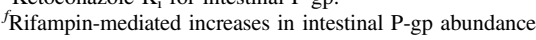

SFs (for rifampin-mediated P-gp induction) were performed to adequately recover clinical results.

For bosutinib DDI predictions, the vendor-verified compound files in Simcyp library were used, i.e., ketoconazole (sim-ketoconazole $400 \mathrm{mg}$ QD), rifampin (sv-rifampicin-md), itraconazole (sv-itraconazole_fed capsule), itraconazole metabolite (sv-OH-itraconazole), verapamil (sv-verapamil), and verapamil metabolite (sv-norverapamil). The input parameters on CYP3A4-mediated DDIs in these compound files were as follows: ketoconazole competitive $\mathrm{K}_{\mathrm{i}}=0.015 \mu \mathrm{M}$ $\left(\mathrm{f}_{\mathrm{u}, \text { mic }}=0.97\right)$; rifampin induction $\mathrm{E}_{\max }=16, \mathrm{EC}_{50}=0.32 \mu \mathrm{M}$, and competitive $\mathrm{K}_{\mathrm{i}}=15 \mu \mathrm{M}\left(\mathrm{f}_{\mathrm{u}, \text { mic }}=1\right)$, itraconazole competitive $\mathrm{K}_{\mathrm{i}}=0.0013 \mu \mathrm{M}\left(\mathrm{f}_{\mathrm{u}, \text { mic }}=1\right)$; itraconazole metabolite competitive $\mathrm{K}_{\mathrm{i}}=0.0023 \mu \mathrm{M}\left(\mathrm{f}_{\mathrm{u} \text {,mic }}=1\right)$; ; verapamil mechanism-based inhibition $\mathrm{K}_{\mathrm{I}}=2.21 \mu \mathrm{M}\left(\mathrm{f}_{\mathrm{u} \text {,mic }}=1\right)$ and maximal inactivation rate $\left(\mathrm{k}_{\text {inact }}\right)=2$ hour $^{-1}$ ); verapamil metabolite mechanism-based inhibition $\mathrm{K}_{\mathrm{I}}=$ $10.3 \mu \mathrm{M}\left(\mathrm{f}_{\mathrm{u}, \text { mic }}=1\right)$ and $\mathrm{k}_{\text {inact }}=18$ hour $\left.^{-1}\right)$. The input parameters of intestinal P-kinetics were as follows: verapamil $\mathrm{K}_{\mathrm{m}}=0.734 \mu \mathrm{M}\left(\mathrm{f}_{\mathrm{u}, \operatorname{mic}}=1\right), \mathrm{J}_{\max }=2.814$ $\mathrm{pmol} / \mathrm{min}$, and (inhibition constant) $\mathrm{K}_{\mathrm{i}}=0.16 \mu \mathrm{M}\left(\mathrm{f}_{\mathrm{u}, \mathrm{mic}}=1\right)$; verapamil metabolite $\mathrm{K}_{\mathrm{i}}=0.04 \mu \mathrm{M}\left(\mathrm{f}_{\mathrm{u}, \text { mic }}=1\right)$. For itraconazole-mediated P-gp inhibition, no P-gp inhibition parameters were incorporated into the default compound file; therefore, on the basis of the reported values (a median of $1.7 \mu \mathrm{M}$ with a range of 0.45-6.7 $\mu \mathrm{M}$ using digoxin as a substrate) in the DIDB, the lower end of itraconazole $\mathrm{P}-\mathrm{gp} \mathrm{K}_{\mathrm{i}}$ values was used as the input parameter (i.e., $0.5 \mu \mathrm{M}$ ). P-gp $\mathrm{K}_{\mathrm{i}}$ value of verapamil $(0.16 \mu \mathrm{M})$ in the default compound file was also near the lower end of reported values (a median $4.9 \mu \mathrm{M}$ with a range of $0.06-57 \mu \mathrm{M}$ using digoxin as a substrate with an exception of $224 \mu \mathrm{M}$ ) in the DIDB.

\section{Data Analysis}

Pharmacokinetic parameters such as $\mathrm{C}_{\max }, \mathrm{t}_{\max }$, and AUC from time zero to infinity, $\mathrm{C}_{\max }$ ratio $\left(C_{\max } R\right)$ and $\mathrm{AUC}$ ratio $(A U C R)$ in treatment groups relative to control groups were obtained from Simcyp outputs. To evaluate predictive model performance, the ratios of predicted-to-observed pharmacokinetic parameters $(\mathrm{P} / \mathrm{O})$ were calculated according to the following equation:

$$
P / O=\frac{\text { Predicted Parameters }}{\text { Observed Parameters }}
$$

To assess the predictive model performance, the P/O ratios within $\pm 50 \%$ of the observed results (i.e., $0.67-1.5$ ) were provisionally considered to be acceptable as the predefined criteria (Guest et al., 2011; Sager et al., 2015).

\section{Results}

\section{Bosutinib PBPK Models without P-gp Kinetics}

Model Refinement on Intravenous Pharmacokinetics. On the basis of the intravenous plasma concentration-time profiles in healthy subjects at a dose of $120 \mathrm{mg}$, we compared the predictive performance of the PBPK models between two different parameter sets, i.e., $\mathrm{CL}_{\text {int }}$ of
$300 \mu \mathrm{l} / \mathrm{min}$ per milligram protein and $\mathrm{V}_{\mathrm{ss}}$ of $15 \mathrm{l} / \mathrm{kg}$ used in the previous model and $\mathrm{CL}_{\text {int }}$ of $560 \mu \mathrm{l} / \mathrm{min}$ per milligram protein and $\mathrm{V}_{\mathrm{ss}}$ of $28 \mathrm{l} / \mathrm{kg}$ obtained from the $\mathrm{F}_{\text {oral }}$ study. The intravenous plasma concentrationtime profiles were overpredicted by the PBPK model with the parameters used in the previous model (Fig. 1A), resulting in $C_{\max }$ and AUC values higher than the observed values with $\mathrm{P} / \mathrm{O}$ ratios of 1.9 and 1.5 , respectively (Table 3 ). In contrast, the predicted $\mathrm{P} / \mathrm{O}$ ratio for AUC was within $\sim 10 \%$ of the observed values in the PBPK model with the parameters from the $\mathrm{F}_{\text {oral }}$ study, whereas that for $\mathrm{C}_{\max }(\sim 60 \%)$ was close to the acceptable range $(\leq \pm 50 \%$ ) (Fig. 1B; Table 3 ). Accordingly, the PBPK model was refined with the $\mathrm{CL}_{\text {int }}$ of $560 \mu \mathrm{l} / \mathrm{min}$ per milligram protein and the $\mathrm{V}_{\text {ss }}$ of $28 \mathrm{l} / \mathrm{kg}$ obtained from the $\mathrm{F}_{\text {oral }}$ study.

Model Refinement on Oral Pharmacokinetics. The oral plasma concentration-time profiles of bosutinib in healthy subjects at a dose of $500 \mathrm{mg}$ were predicted by the refined PBPK- $\mathrm{F}_{\mathrm{a}}$ model with fixed $\mathrm{F}_{\mathrm{a}}$ of 0.7 and $\mathrm{f}_{\mathrm{u} \text {,gut }}$ of 1 used in the previous PBPK model. The PBPK-F model considerably underpredicted the plasma concentration-time profiles (Fig. 1C), resulting in that the predicted $\mathrm{C}_{\max }$ and AUC values were $\geq 2$-fold lower than the observed values (Table 3 ). Since bosutinib $F_{a}$ was estimated at 0.7 in the mass-balance study, the SAO for $f_{u, g u t}$ ranging from 0.01 to 1 was performed to investigate the effect of $f_{u \text {,gut }}$ on overall outcomes, particularly, a fraction of the dose that escapes intestinal first-pass metabolism $\left(\mathrm{F}_{\mathrm{g}}\right)$. Results showed that the plasma concentration-time profiles were reasonably predicted by the PBPK-F models with $\mathrm{f}_{\mathrm{u} \text {,gut }}$ of $0.01-0.1$ ( $\leq 20 \%$ difference in AUC). Accordingly,

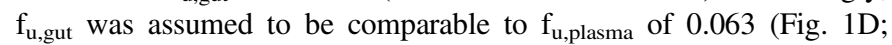
Table 3). The difference between $\mathrm{f}_{\mathrm{u} \text {,gut }}$ of 0.063 and 1 resulted in an approximately 2 -fold difference in the predicted $\mathrm{F}_{\mathrm{g}}$ (median) of 0.93 and 0.45 , respectively.

Model Verification on DDI Outcomes. Bosutinib single-dose DDIs with ketoconazole and rifampin were predicted by the refined PBPK-F models with $\mathrm{f}_{\mathrm{u} \text {,gut }}$ of 0.063 . The $\mathrm{F}_{\mathrm{a}}$ value was set at 0.7 at bosutinib dose of $500 \mathrm{mg}$, whereas it was calculated at 0.3 at doses of $100 \mathrm{mg}$ on the basis of a comparison of AUC estimates between 100 and $500 \mathrm{mg}$. The predicted $\mathrm{C}_{\max }$ and AUC were within $\pm 40 \%$ of the observed results in control groups (bosutinib alone) from these three DDI studies (Tables 4-6). In contrast, at bosutinib $100 \mathrm{mg}$ with ketoconazole, the PBPK-F $\mathrm{F}_{\mathrm{a}}$ model considerably underpredicted the plasma concentrations of bosutinib in the treatment group (bosutinib with ketoconazole), with the P/O ratios of 0.5 for both $\mathrm{C}_{\max }$ and AUC (Table 4). The P/O ratios for $\mathrm{C}_{\max } \mathrm{R}$ and AUCR were approximately 0.6 . Thus, the PBPK-F $\mathrm{F}_{\mathrm{a}}$ model significantly underpredicted the effect of ketoconazole on bosutinib 
A
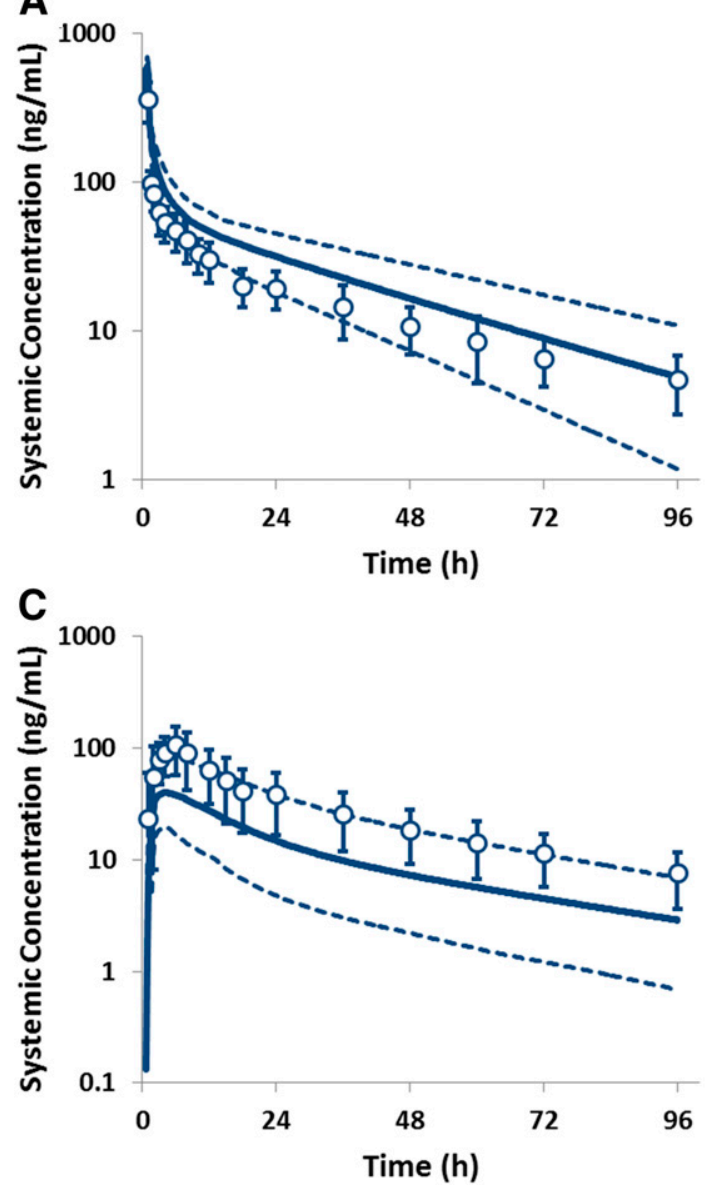

B
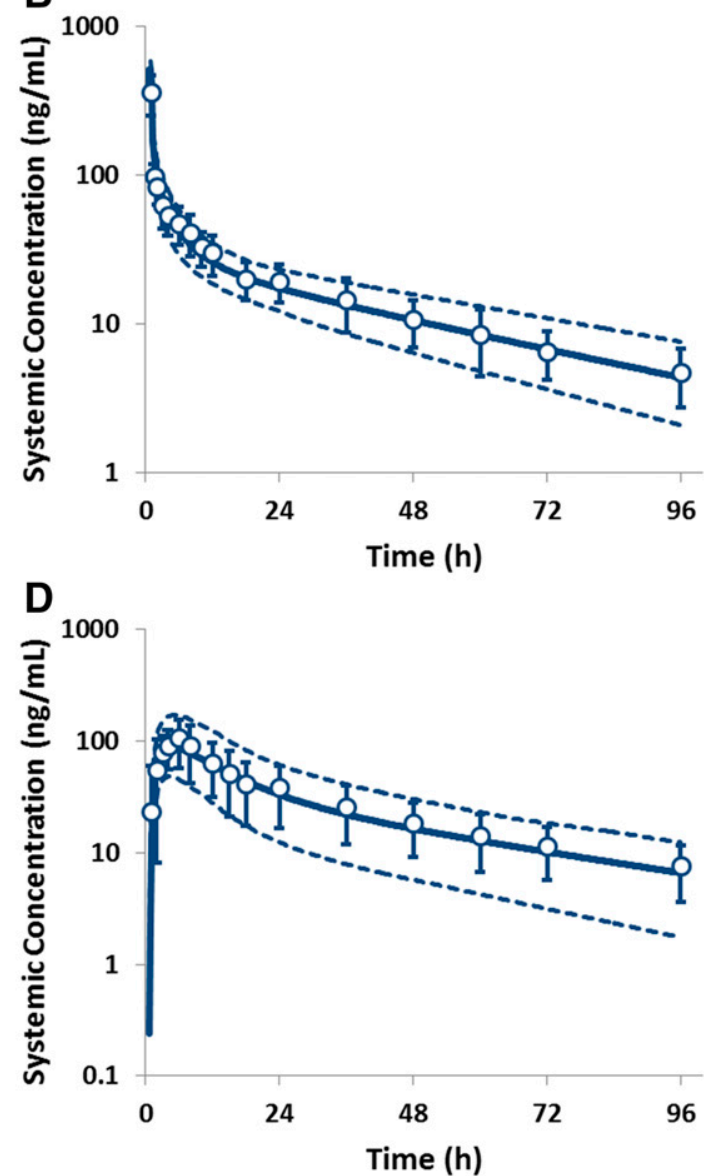

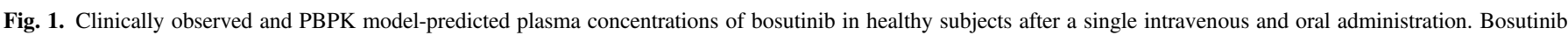

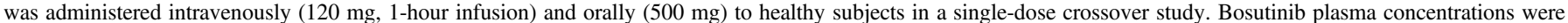

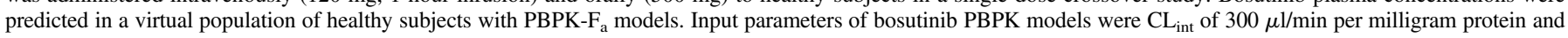

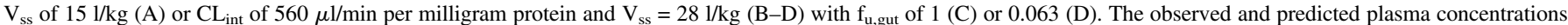
are expressed as mean \pm S.D. (O) and mean (-) with 5 th and 95 th percentiles (---), respectively.

exposures at a dose of $100 \mathrm{mg}$ (Fig. 2A). At bosutinib $500 \mathrm{mg}$ with ketoconazole, the PBPK- $F_{a}$ model tended to underpredict the plasma concentrations of bosutinib in the treatment group with $\mathrm{P} / \mathrm{O}$ ratios of 0.70 and 0.88 for $\mathrm{C}_{\max }$ and AUC, respectively (Fig. 2B; Table 5). The $\mathrm{P} / \mathrm{O}$ ratios of $\mathrm{C}_{\max } \mathrm{R}$ and AUCR were 0.97 and 0.66 , respectively. Thus, the underprediction was more pronounced at a dose of $100 \mathrm{mg}$ than $500 \mathrm{mg}$ in the DDI studies with ketoconazole. At bosutinib $500 \mathrm{mg}$ with rifampin, the PBPK-F $F_{a}$ model significantly overpredicted the plasma concentrations of bosutinib with rifampin, resulting in the $\mathrm{P} / \mathrm{O}$ ratios of 1.6 for $C_{\max }$ and 2.4 for AUC (Fig. 2C; Table 6). The predicted $C_{\max } R$ and AUCR were approximately 2-fold higher than the observed ratios, i.e., the P/O ratios of 1.9 for both $\mathrm{C}_{\max } \mathrm{R}$ and AUCR.

In these DDI predictions, the predicted $\mathrm{F}_{\mathrm{h}}$ values in control groups were approximately 0.6 (median), which increased to near-unity $(\sim 1.0)$ by ketoconazole-mediated CYP3A4 inhibition and decreased to $\sim 0.1$ by rifampin-mediated CYP3A4 induction. Thus, the modeling results suggested that hepatic metabolism of bosutinib was near-completely inhibited by ketoconazole or induced by rifampin. The predicted $\mathrm{F}_{\mathrm{g}}$ values $(\sim 0.9)$ in control groups also increased to near-unity $(\sim 1.0)$ by ketoconazole, suggesting that the contribution of intestinal metabolism to systemic DDIs was minimal. The predicted $F_{\mathrm{g}}$ values in the DDI study with rifampin decreased to $\sim 0.6$, which appeared to be constrained by the faster CYP3A4 degradation rates in intestine $\left(0.03\right.$ hour $\left.^{-1}\right)$ than liver $\left(0.0193\right.$ hour $\left.^{-1}\right)$ and the small $f_{u, g u t}(0.063)$ optimized by the aforementioned SAO. Overall, the modeling results suggested that the predicted changes in bosutinib $F_{h}$ and $F_{g}$ by ketoconazole and rifampin could not sufficiently recover the observed DDI results. Therefore, these precipitant drugs could possibly impact the extent of bosutinib absorption $\left(\mathrm{F}_{\mathrm{a}}\right)$ through $\mathrm{P}$-gp-mediated efflux in intestine.

\section{Bosutinib PBPK Models with P-gp Kinetics}

Model Refinement on Oral Pharmacokinetics. To incorporate bosutinib P-gp kinetics into the intestinal absorption process, the PBPKADAM models were used with the refined bosutinib parameters. For bosutinib P-gp kinetic parameters, in vitro $\mathrm{K}_{\mathrm{m}}(0.38 \mu \mathrm{M})$ and $\mathrm{J}_{\max }$ (15 pmol/min) determined in Caco-2 cells were initially incorporated into the PBPK-ADAM models. Clinical studies used for the model refinement were an oral group of bosutinib $F_{\text {oral }}$ study at a dose of $500 \mathrm{mg}$ and control groups of DDI studies with ketoconazole (100 and bosutinib $500 \mathrm{mg}$ ) and rifampin (bosutinib $500 \mathrm{mg}$ ).

The model-predicted plasma concentration-time profiles of bosutinib in control group at a dose of $100 \mathrm{mg}$ were considerably overpredicted by the PBPK-ADAM model with P-gp inputs, resulting in $\mathrm{P} / \mathrm{O}$ ratios of 4.5 and 2.0 for $\mathrm{C}_{\max }$ and AUC, respectively (Supplemental Fig. S1A; Table 4). The predicted $\mathrm{F}_{\mathrm{a}}$ was approximately 0.7 (median). Compared with the predicted results by the PBPK-ADAM model without P-gp kinetics, the overprediction was slightly improved from the $\mathrm{P} / \mathrm{O}$ ratios of 
TABLE 3

Clinically observed and PBPK model-predicted pharmacokinetic parameters of bosutinib in humans following a single intravenous and oral administration of bosutinib

Data are expressed as geometric mean with percent coefficient of variation (CV\%) in parentheses $(n=13-14$ for the observed; $n=6$ per group $\times 6$ groups for the predicted) except for median $\mathrm{t}_{\max }$ with minimal to maximal values.

\begin{tabular}{|c|c|c|c|c|c|c|}
\hline Dose & & $\mathbf{J}_{\max }{ }^{b}$ & & $\mathrm{C}_{\max }$ & $\mathrm{t}_{\max }$ & AUC \\
\hline$m g$ & & $S F$ & & $n g / m l$ & $h$ & $n g \bullet h / m l$ \\
\hline \multirow[t]{5}{*}{120} & - & - & Obs & 347 (28) & $1(1-1)$ & $1920(26)$ \\
\hline & IV-1 & - & Pred & $662(14)$ & $1(1-1)$ & $2934(35)$ \\
\hline & & & $\mathrm{P} / \mathrm{O}$ & 1.91 & - & 1.53 \\
\hline & IV-2 & - & Pred & $563(13)$ & $1(1-1)$ & $2128(28)$ \\
\hline & & & $\mathrm{P} / \mathrm{O}$ & 1.62 & - & 1.11 \\
\hline \multirow[t]{13}{*}{500} & - & - & Obs & $109(43)$ & $6(2-8)$ & $2736(44)$ \\
\hline & $\mathrm{F}_{\mathrm{a}}-1$ & - & Pred & $36(55)$ & $4(3-7)$ & 1012 (77) \\
\hline & & & $\mathrm{P} / \mathrm{O}$ & 0.33 & - & 0.37 \\
\hline & $\mathrm{F}_{\mathrm{a}}-2$ & - & Pred & $83(47)$ & $4(3-7)$ & $2374(46)$ \\
\hline & & & $\mathrm{P} / \mathrm{O}$ & 0.76 & - & 0.87 \\
\hline & ADAM & - & Pred & $138(48)$ & $5(2-11)$ & $3038(64)$ \\
\hline & & & $\mathrm{P} / \mathrm{O}$ & 1.27 & - & 1.11 \\
\hline & & 1 & Pred & $123(49)$ & $5(2-15)$ & $2770(66)$ \\
\hline & & & $\mathrm{P} / \mathrm{O}$ & 1.12 & - & 1.01 \\
\hline & & 2 & Pred & $112(51)$ & $5(2-17)$ & $2560(68)$ \\
\hline & & & $\mathrm{P} / \mathrm{O}$ & 1.03 & - & 0.94 \\
\hline & & 4 & Pred & $96(53)$ & $5(2-20)$ & $2235(71)$ \\
\hline & & & $\mathrm{P} / \mathrm{O}$ & 0.88 & - & 0.82 \\
\hline
\end{tabular}

- , not application or not calculated.

${ }^{a} \mathrm{CL}_{\text {int }}=300 \mu \mathrm{l} / \mathrm{min}$ per milligram protein and $\mathrm{V}_{\mathrm{ss}}=15 \mathrm{l} / \mathrm{kg}(\mathrm{IV}-1)$ or $\mathrm{CL}_{\mathrm{int}}=560 \mu \mathrm{l} / \mathrm{min}$ per milligram protein and $\mathrm{V}_{\mathrm{ss}}=28 \mathrm{l} / \mathrm{kg}\left(\mathrm{IV}-2, \mathrm{~F}_{\mathrm{a}}-1, \mathrm{~F}_{\mathrm{a}}-2\right.$, and ADAM) with $\mathrm{f}_{\mathrm{u}, \text { gut }}=1\left(\mathrm{~F}_{\mathrm{a}}-1\right)$ or 0.063 $\left(\mathrm{F}_{\mathrm{a}}-2\right.$ and $\left.\mathrm{ADAM}\right)$

${ }^{b}$ Predicted in vitro-to-in vivo scaling factor (SF) for intestinal P-gp $\mathrm{J}_{\max }$

${ }^{c} \mathrm{Obs}$, observed; Pred, predicted; $\mathrm{P} / \mathrm{O}$, ratios of predicted to observed value.

5.4 and 2.2 for $\mathrm{C}_{\max }$ and AUC, respectively (Table 4). Following the SAO for $\mathrm{J}_{\max }$ SFs in PBPK-ADAM models, the predicted $\mathrm{C}_{\max }$ and AUC with an SF of 25 were within $\pm 20 \%$ of the observed results (Supplemental Fig. S2A; Table 4). The predicted $\mathrm{F}_{\mathrm{a}}$ was $\sim 0.3$, which was $\sim 3$-fold lower than that $(\sim 0.7)$ by the PBPK-ADAM model with an SF of unity.

At bosutinib dose of $500 \mathrm{mg}$, the PBPK-ADAM model with $\mathrm{J}_{\max } \mathrm{SF}$ of unity sufficiently predicted the plasma concentration-time profiles of bosutinib in an oral group of bosutinib $\mathrm{F}_{\text {oral }}$ study and control groups of bosutinib $500 \mathrm{mg}$ DDI studies (Supplemental Fig. S1). The P/O ratios were 1.1-1.2 for $\mathrm{C}_{\max }$ and 1.0-1.4 for AUC (Tables 3, 5, and 6). The model performance was slightly improved from the PBPK-ADAM model without $\mathrm{P}$-gp parameters (P/O ratios of 1.3-1.4 for $\mathrm{C}_{\max }$ and 1.1-1.6 for AUC). Thus, the effects of intestinal P-gp-mediated efflux on bosutinib exposures could be minimal at the clinically recommended dose of $500 \mathrm{mg}$. The $\mathrm{SAO}$ for $\mathrm{J}_{\max }$ suggested that the predictive model performance could be improved further to $\mathrm{P} / \mathrm{O}$ ratios of $0.95-1.0$ for $\mathrm{C}_{\max }$ and $0.94-1.2$ for AUC when $\mathrm{J}_{\max } \mathrm{SF}$ was set at 2 in the $\mathrm{F}_{\text {oral }}$ study and at 4 in the DDI studies (Supplemental Fig. S2; Tables 3, 5, and 6). Subsequently, $\mathrm{J}_{\max } \mathrm{SF}$ of 4 was used for the following model verification on the basis of DDI results. The difference in bosutinib exposures at a dose of $500 \mathrm{mg}$ among these studies could be considered to be within the variability between clinical studies including interindividual variability. The predicted $\mathrm{F}_{\mathrm{a}}$ in these studies was $0.5-0.7$, which was comparable to the estimated $\mathrm{F}_{\mathrm{a}}$ of 0.7 in the mass-balance study.

Model Verification on DDI Outcomes. The DDI prediction of bosutinib with ketoconazole was performed by the PBPK-ADAM models with the optimized $\mathrm{J}_{\max }$ SFs at doses of 100 and $500 \mathrm{mg}$. As suggested by the PBPK- $\mathrm{F}_{\mathrm{a}}$ modeling results, the effect of ketoconazole on bosutinib exposures was underpredicted by the PBPK-ADAM model without ketoconazole-mediated P-gp inhibition (Fig. 3A and C), particularly at a dose of $100 \mathrm{mg}$. The $\mathrm{P} / \mathrm{O}$ ratios for $\mathrm{C}_{\max } \mathrm{R}$ and AUCR were 0.47 and 0.66 , respectively, at $100 \mathrm{mg}$ (Table 4), whereas those were 0.72 and 0.60 , respectively, at $500 \mathrm{mg}$ (Table 5). The predicted $\mathrm{F}_{\mathrm{h}}$ and $F_{\mathrm{g}}$ in control groups increased to near-unity in treatment groups with ketoconazole. Thus, the modeling results suggested that the hepatic and intestinal metabolism of bosutinib was near-completely inhibited by ketoconazole; yet the PBPK-ADAM models underpredicted the effect of

TABLE 4

Clinically observed and PBPK model-predicted pharmacokinetic parameters of bosutinib in bosutinib 100-mg singledose DDI studies with ketoconazole

Data are expressed as mean with percent coefficient of variation (CV\%) in parentheses $(n=24$ for the observed; $n=6$ per group $\times$ 6 groups for the predicted) except for median $t_{\max }$ with minimal to maximal values and geometric mean for $C_{\max } R$ and AUCR with $90 \%$ confidence interval.

\begin{tabular}{|c|c|c|c|c|c|c|c|c|}
\hline \multirow{2}{*}{ Group $^{a}$} & \multirow{2}{*}{ PBPK Model } & \multirow{2}{*}{$\frac{\mathrm{J}_{\max }^{b}}{S F}$} & \multirow{2}{*}{$\frac{\mathrm{K}_{\mathrm{i}}^{c}}{\mu M}$} & \multirow{2}{*}{ Analysis $^{d}$} & \multirow{2}{*}{$\frac{\mathrm{C}_{\max }}{n g / m l}$} & \multirow{2}{*}{$\frac{\mathrm{AUC}}{n g \cdot h / m l}$} & \multirow{2}{*}{$\frac{\mathrm{C}_{\max } \mathrm{R}^{e}}{\text { ratio }}$} & \multirow{2}{*}{$\begin{array}{c}\mathrm{AUCR}^{e} \\
\text { ratio }\end{array}$} \\
\hline & & & & & & & & \\
\hline \multirow[t]{9}{*}{ Control } & - & - & - & Obs & $7.0(45)$ & $323(43)$ & - & - \\
\hline & $\mathrm{F}_{\mathrm{a}}$ & - & - & Pred & $7.2(45)$ & $265(68)$ & - & - \\
\hline & & & & $\mathrm{P} / \mathrm{O}$ & 1.03 & 0.82 & - & - \\
\hline & ADAM & - & - & Pred & $38(44)$ & $709(68)$ & - & - \\
\hline & & & & $\mathrm{P} / \mathrm{O}$ & 5.41 & 2.19 & - & - \\
\hline & & 1 & - & Pred & $31(47)$ & $653(72)$ & - & - \\
\hline & & & & $\mathrm{P} / \mathrm{O}$ & 4.47 & 2.02 & - & - \\
\hline & & 25 & - & Pred & $8.0(86)$ & $276(95)$ & - & - \\
\hline & & & & $\mathrm{P} / \mathrm{O}$ & 1.15 & 0.85 & - & - \\
\hline \multirow[t]{7}{*}{ Test } & - & - & - & Obs & $38(54)$ & $2631(30)$ & $5.2(4.3-6.2)$ & $8.6(7.5-9.9)$ \\
\hline & $\mathrm{F}_{\mathrm{a}}$ & - & - & Pred & $20(39)$ & $1221(88)$ & $2.9(2.6-3.2)$ & $4.7(3.7-5.7)$ \\
\hline & & & & $\mathrm{P} / \mathrm{O}$ & 0.53 & 0.46 & 0.57 & 0.55 \\
\hline & ADAM & 25 & - & Pred & $21(77)$ & $1494(85)$ & $2.5(2.3-2.9)$ & $5.7(5.3-8.1)$ \\
\hline & & & & $\mathrm{P} / \mathrm{O}$ & 0.56 & 0.57 & 0.47 & 0.66 \\
\hline & & 25 & 0.2 & Pred & $37(56)$ & $2098(78)$ & $5.2(4.6-5.7)$ & $11(9.3-14)$ \\
\hline & & & & $\mathrm{P} / \mathrm{O}$ & 0.96 & 0.80 & 1.00 & 1.32 \\
\hline
\end{tabular}

-, not applicable or not calculated.

${ }^{a}$ Bosutinib $100 \mathrm{mg}$ without and with ketoconazole $400 \mathrm{mg}$ once daily (control and test groups, respectively).

${ }^{b}$ Predicted in vitro-to-in vivo scaling factor (SF) for intestinal P-gp J $\mathrm{J}_{\max }$

${ }^{c}$ Predicted ketoconazole $\mathrm{K}_{\mathrm{i}}$ value for intestinal P-gp.

${ }^{d}$ Obs, observed; Pred, predicted; $\mathrm{P} / \mathrm{O}$, ratios of predicted to observed value.

${ }^{e}$ Ratios of $\mathrm{C}_{\max }$ and AUC in test group relative to control group. 
A
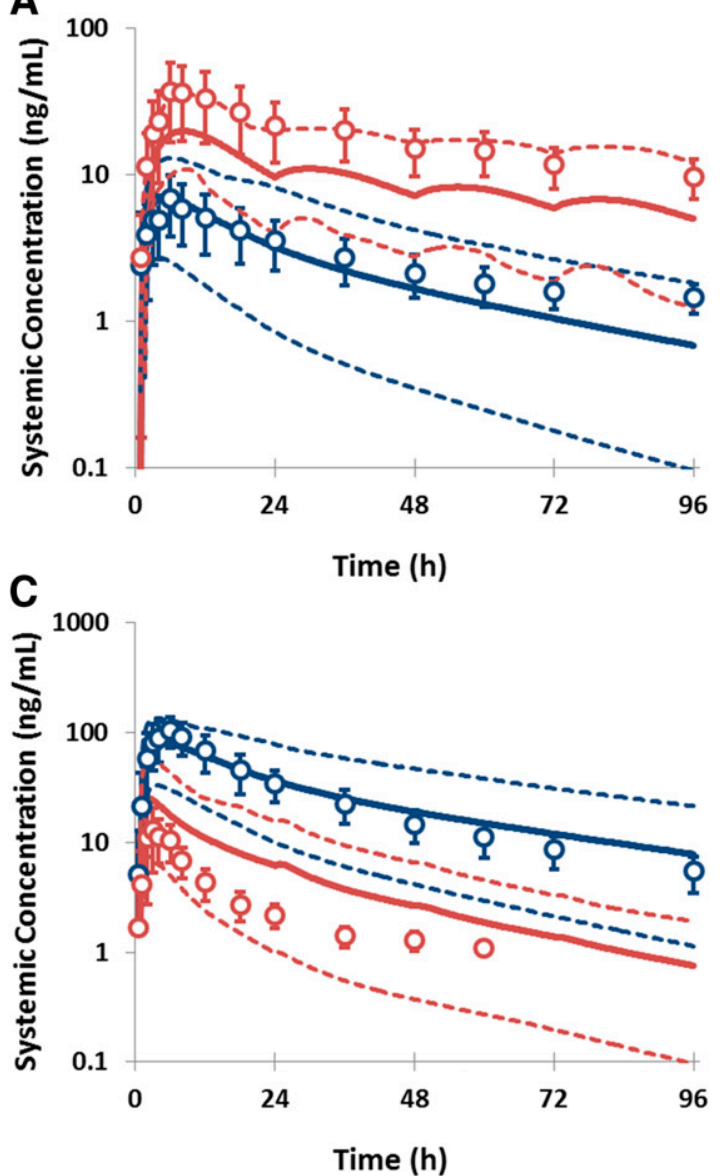

Time (h)

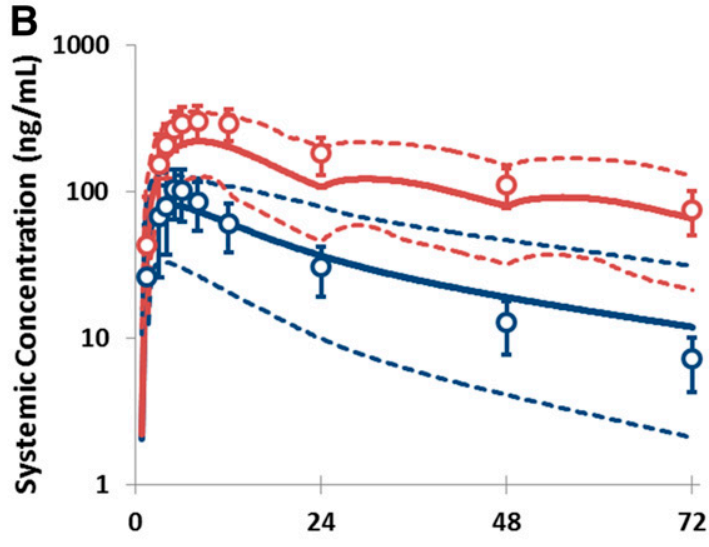

Time (h)

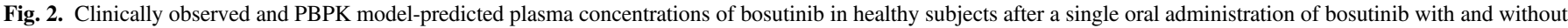

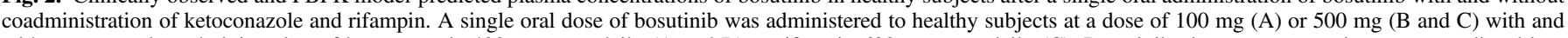

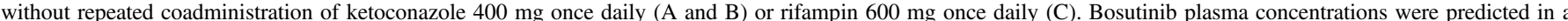

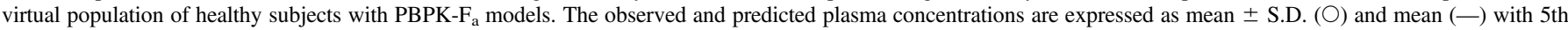
and 95 th percentiles (---), respectively.

ketoconazole on bosutinib exposures. Accordingly, ketoconazole $\mathrm{K}_{\mathrm{i}}$ for $\mathrm{P}$-gp was incorporated into the PBPK-ADAM models to account for ketoconazole-mediated P-gp inhibition. Following the SAO for ketoconazole $K_{i}$, the predicted $C_{\max }$ and AUC by PBPK-ADAM models with $\mathrm{K}_{\mathrm{i}}$ values of $0.1-0.3 \mu \mathrm{M}$ were in the acceptable range $(\leq \pm 50 \%$ ) of the observed results in the treatment group at a 100-mg bosutinib dose. When $\mathrm{K}_{\mathrm{i}}$ was set at $0.2 \mu \mathrm{M}$, the predicted $\mathrm{C}_{\max }$ and AUC were within \pm $25 \%$ of the observed results, resulting in the $\mathrm{P} / \mathrm{O}$ ratios for $\mathrm{C}_{\max } \mathrm{R}$ and AUCR of 1.0 and 1.3, respectively (Fig. 3B; Table 4). Bosutinib $F_{a}$ (median) was predicted to increase from 0.2 to 0.4. Assuming the general hypothesis that $\mathrm{K}_{\mathrm{i}}$ was intrinsic, the effect of ketoconazole on bosutinib oral exposures at a dose of $500 \mathrm{mg}$ was predicted by the PBPK-ADAM models with ketoconazole $\mathrm{K}_{\mathrm{i}}$ of $0.2 \mu \mathrm{M}$. The predicted $\mathrm{C}_{\max }$ and $\mathrm{AUC}$ were within $\leq \pm 25 \%$ of the observed values, resulting in the $\mathrm{P} / \mathrm{O}$ ratios for $\mathrm{C}_{\max } \mathrm{R}$ and AUCR of 0.87 and 0.70 , respectively (Fig. $3 \mathrm{D}$; Table 5). Compared with the predicted results without ketoconazole $\mathrm{K}_{\mathrm{i}}$, the DDI prediction was slightly improved from the P/O ratios for $\mathrm{C}_{\max } \mathrm{R}$ of 0.72 and AUCR of 0.60 . Bosutinib $\mathrm{F}_{\mathrm{a}}$ (median) was predicted to increase from 0.5 to 0.7 at $500 \mathrm{mg}$ by ketoconazole-mediated P-gp inhibition.

The DDI prediction of bosutinib with rifampin was also performed by the PBPK-ADAM model with the optimized intestinal P-gp $\mathrm{J}_{\max }$ SF. The PBPK-ADAM model considerably underpredicted the effect of rifampin on bosutinib exposures even though the predicted $F_{h}$ and
$\mathrm{F}_{\mathrm{g}}$ markedly decreased to 0.11 and 0.64 , respectively (Fig. 4A). The $\mathrm{P} / \mathrm{O}$ ratios for $\mathrm{C}_{\max }$ and $\mathrm{AUC}$ were 2.6-3.0, resulting in the $\mathrm{P} / \mathrm{O}$ ratios of 2.5-2.8 for $\mathrm{C}_{\max } \mathrm{R}$ and AUCR (Table 6). The increases in intestinal $\mathrm{P}$-gp abundances were therefore incorporated into PBPK-ADAM models to account for rifampin-mediated P-gp induction, as was suggested by the PBPK- $F_{a}$ modeling results. Following the SAO for $\mathrm{J}_{\max } \mathrm{SFs}$ as rifampin-mediated fold-increases in $\mathrm{P}$-gp abundances, the predicted $\mathrm{C}_{\max }$ and AUC were in the acceptable range $(\leq \pm 50 \%)$ of the observed results in treatment group whose $\mathrm{J}_{\max }$ SFs were set at 32-48 to correspond to the P-gp induction of 8- to 12-fold on top of an SF of 4 used for control group (Supplemental Table S1). Assuming the fold-increase in P-gp abundance of 10 , the $\mathrm{C}_{\max }$ and AUC were within $\pm 30 \%$ of the observed values, resulting in $\mathrm{P} / \mathrm{O}$ ratios for $\mathrm{C}_{\max } \mathrm{R}$ and AUCR of 0.86 and 0.95 , respectively (Fig. 4B; Table 6). Bosutinib $\mathrm{F}_{\mathrm{a}}$ was predicted to decrease from 0.6 to 0.2 by rifampinmediated P-gp induction.

Model Application to DDI Prediction. Bosutinib DDIs with dual CYP3A/P-gp inhibitors itraconazole and verapamil were predicted by the PBPK-ADAM models. In these DDI predictions, a single oral dose of bosutinib $500 \mathrm{mg}$ was administered to a virtual population of healthy volunteers on day 5 with and without 16-day repeated oral administration of either itraconazole (200 mg one daily) or verapamil ( $80 \mathrm{mg}$ three times a day). The predicted $\mathrm{C}_{\max } \mathrm{R}$ and AUCR were, respectively, 2.0 and 8.5 with itraconazole and 2.0 and 5.1 with verapamil (Table 7). 
TABLE 5

Clinically observed and PBPK model-predicted pharmacokinetic parameters of bosutinib in bosutinib 500-mg singledose DDI studies with ketoconazole

\begin{tabular}{|c|c|c|c|c|c|c|c|c|}
\hline \multirow{2}{*}{ Group $^{a}$} & \multirow{2}{*}{ PBPK Model } & \multirow{2}{*}{$\frac{\mathrm{J}_{\max }^{b}}{S F}$} & \multirow{2}{*}{$\frac{\mathrm{K}_{\mathrm{i}}^{c}}{\mu M}$} & \multirow{2}{*}{ Analysis $^{d}$} & \multirow{2}{*}{$\begin{array}{l}\mathrm{C}_{\max } \\
n g / m l\end{array}$} & \multirow{2}{*}{$\frac{\mathrm{AUC}}{\mathrm{ng} \cdot \mathrm{h} / \mathrm{ml}}$} & \multirow{2}{*}{$\begin{array}{c}\mathrm{C}_{\max } \mathrm{R}^{e} \\
\text { ratio } \\
\end{array}$} & \multirow{2}{*}{$\frac{\mathrm{AUCR}^{e}}{\text { ratio }}$} \\
\hline & & & & & & & & \\
\hline \multirow[t]{9}{*}{ Control } & - & - & - & Obs & 114 (35) & $2330(35)$ & - & - \\
\hline & $F_{a}$ & - & - & Pred & $84(41)$ & 3013 (64) & - & - \\
\hline & & & & $\mathrm{P} / \mathrm{O}$ & 0.74 & 1.29 & - & - \\
\hline & ADAM & - & - & Pred & 153 (48) & 3606 (64) & - & - \\
\hline & & & & $\mathrm{P} / \mathrm{O}$ & 1.34 & 1.55 & - & - \\
\hline & & 1 & - & Pred & 136 (49) & 3316 (66) & - & - \\
\hline & & & & $\mathrm{P} / \mathrm{O}$ & 1.20 & 1.42 & - & - \\
\hline & & 4 & - & Pred & 109 (53) & 2738 (71) & - & - \\
\hline & & & & $\mathrm{P} / \mathrm{O}$ & 0.95 & 1.18 & - & - \\
\hline \multirow[t]{7}{*}{ Test } & - & - & - & Obs & 326 (24) & $15,200(29)$ & 2.9 & 6.5 \\
\hline & $\mathrm{F}_{\mathrm{a}}$ & - & - & Pred & $228(32)$ & $13,311(69)$ & $2.8(2.5-3.1)$ & $4.2(3.3-5.2)$ \\
\hline & & & & $\mathrm{P} / \mathrm{O}$ & 0.70 & 0.88 & 0.97 & 0.66 \\
\hline & ADAM & 4 & - & Pred & $226(43)$ & $10,639(61)$ & $2.1(2.0-2.3)$ & $4.0(3.1-4.9)$ \\
\hline & & & & $\mathrm{P} / \mathrm{O}$ & 0.69 & 0.70 & 0.72 & 0.60 \\
\hline & & 4 & 0.2 & Pred & $272(40)$ & $12,127(57)$ & $2.6(2.4-2.8)$ & $4.7(3.7-5.7)$ \\
\hline & & & & $\mathrm{P} / \mathrm{O}$ & 0.83 & 0.80 & 0.87 & 0.70 \\
\hline
\end{tabular}

- , not applicable or not calculated.

${ }^{a}$ Bosutinib $500 \mathrm{mg}$ without and with ketoconazole $400 \mathrm{mg}$ once daily (control and test groups, respectively).

${ }^{b}$ Predicted in vitro-to-in vivo scaling factor (SF) for intestinal P-gp $\mathbf{J}_{\max }$.

${ }^{c}$ Predicted ketoconazole $\mathrm{K}_{\mathrm{i}}$ value for intestinal P-gp.

${ }^{d}$ Obs, observed; Pred, predicted; $\mathrm{P} / \mathrm{O}$, ratios of predicted to observed value.

${ }^{e}$ Ratios of $\mathrm{C}_{\max }$ and AUC in test group relative to control group.

Compared with the DDI prediction without P-gp inhibition (i.e., only CYP3A inhibition), the differences in $\mathrm{C}_{\max } \mathrm{R}$ and AUCR were negligible to minimal. These results together with the DDI prediction with ketoconazole suggested minimal impacts of P-gp-mediated efflux on bosutinib DDIs with P-gp inhibitors at clinically recommended dose of bosutinib $500 \mathrm{mg}$.

\section{Discussion}

Utilizing PBPK modeling for understanding pharmacokinetic mechanism of NMEs has become common practice in drug development as well as regulatory decision-making (Rowland et al., 2011; Huang and Rowland, 2012; Prueksaritanont et al., 2013; Wagner et al., 2015, 2016; Shebley et al., 2018). Modeling approaches typically consist of three

TABLE 6

Clinically observed and PBPK model-predicted pharmacokinetic parameters of bosutinib in bosutinib 500-mg singledose DDI studies with rifampin

Data are expressed as mean with percent coefficient of variation $(\mathrm{CV} \%)$ in parentheses $(\mathrm{n}=22-24$ for the observed; $\mathrm{n}=6$ per group $\times$ 6 groups for the predicted) except for median $t_{\max }$ with minimal to maximal values and geometric mean for $C_{\max } R$ and AUCR with $90 \%$ confidence interval.

\begin{tabular}{|c|c|c|c|c|c|c|c|c|}
\hline \multirow{2}{*}{ Group $^{a}$} & \multirow{2}{*}{ PBPK Model } & \multirow{2}{*}{$\frac{\mathrm{J}_{\max }^{b}}{S F}$} & \multirow{2}{*}{$\frac{\text { Induction }^{c}}{\text { fold }}$} & \multirow{2}{*}{ Analysis $^{d}$} & \multirow{2}{*}{$\frac{\mathrm{C}_{\max }}{n g / m l}$} & \multirow{2}{*}{$\frac{\text { AUC }}{n g \cdot h / m l}$} & \multirow{2}{*}{$\frac{\mathrm{C}_{\max } \mathrm{R}^{e}}{\text { ratio }}$} & \multirow{2}{*}{$\frac{\mathrm{AUCR}^{e}}{\text { ratio }}$} \\
\hline & & & & & & & & \\
\hline \multirow[t]{9}{*}{ Control } & - & - & - & Obs & $112(26)$ & 2740 (29) & - & - \\
\hline & $\mathrm{F}_{\mathrm{a}}$ & - & - & Pred & $83(40)$ & $3005(65)$ & - & - \\
\hline & & & & $\mathrm{P} / \mathrm{O}$ & 0.74 & 1.10 & - & - \\
\hline & ADAM & - & - & Pred & $153(48)$ & $3606(64)$ & - & - \\
\hline & & & & $\mathrm{P} / \mathrm{O}$ & 1.37 & 1.32 & - & - \\
\hline & & 1 & - & Pred & $136(49)$ & $3316(66)$ & - & - \\
\hline & & & & $\mathrm{P} / \mathrm{O}$ & 1.22 & 1.21 & - & - \\
\hline & & 4 & - & Pred & $109(53)$ & $2738(71)$ & - & - \\
\hline & & & & $\mathrm{P} / \mathrm{O}$ & 0.97 & 1.00 & - & - \\
\hline \multirow[t]{7}{*}{ Test } & - & - & - & Obs & $16(42)$ & $207(22)$ & $0.14(0.12-0.16)$ & $0.08(0.07-0.09)$ \\
\hline & $\mathrm{F}_{\mathrm{a}}$ & - & - & Pred & $26(71)$ & $487(76)$ & $0.27(0.23-0.31)$ & $0.14(0.12-0.17)$ \\
\hline & & & & $\mathrm{P} / \mathrm{O}$ & 1.62 & 2.35 & 1.92 & 1.86 \\
\hline & ADAM & 4 & - & Pred & $41(64)$ & $628(89)$ & $0.34(0.30-0.38)$ & $0.21(0.18-0.24)$ \\
\hline & & & & $\mathrm{P} / \mathrm{O}$ & 2.56 & 3.03 & 2.46 & 2.84 \\
\hline & & 4 & 10 & Pred & $16(64)$ & $260(106)$ & $0.13(0.11-0.15)$ & $0.08(0.06-0.09)$ \\
\hline & & & & $\mathrm{P} / \mathrm{O}$ & 1.01 & 1.26 & 0.86 & 0.95 \\
\hline
\end{tabular}

-, not applicable or not calculated.

${ }^{a}$ Bosutinib $500 \mathrm{mg}$ without and with rifampin $600 \mathrm{mg}$ once daily (control and test groups, respectively)

${ }^{b}$ Predicted in vitro-to-in vivo scaling factor (SF) for intestinal P-gp $\mathrm{J}_{\max }$

${ }^{c}$ Predicted rifampin-mediated fold increase in intestinal P-gp.

${ }^{d}$ Obs, observed; Pred, predicted; $\mathrm{P} / \mathrm{O}$, ratios of predicted to observed value.

${ }^{e}$ Ratios of $\mathrm{C}_{\max }$ and AUC in test group relative to control group. 
A

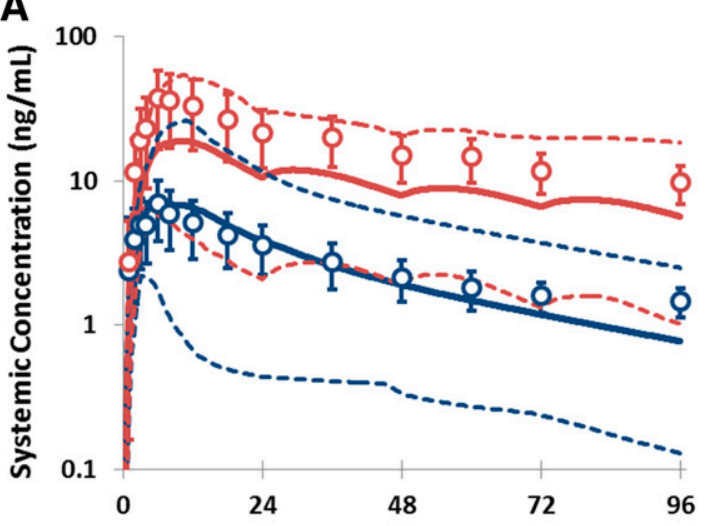

Time (h)

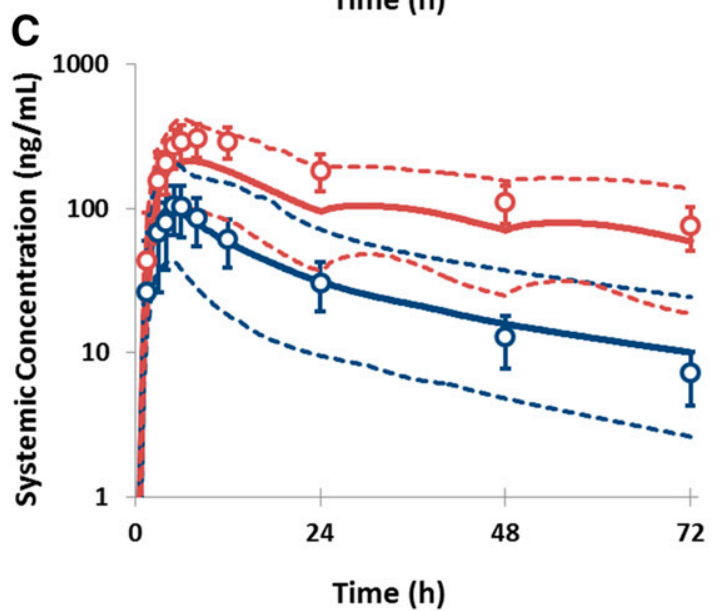

B

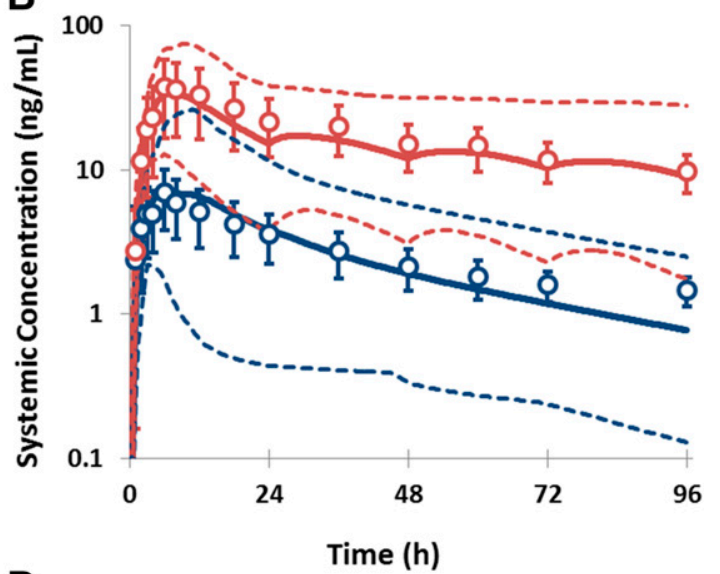

D

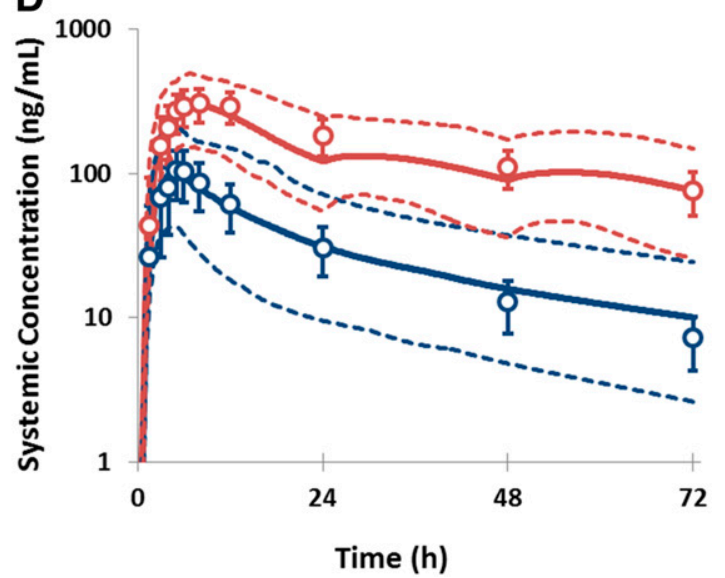

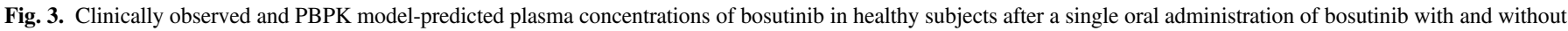

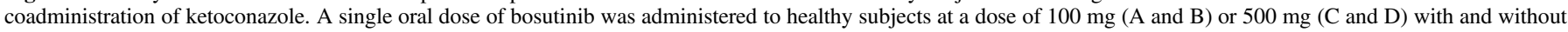

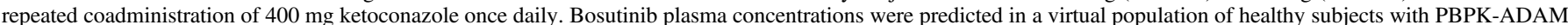

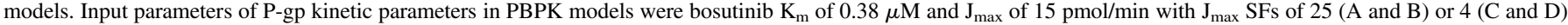

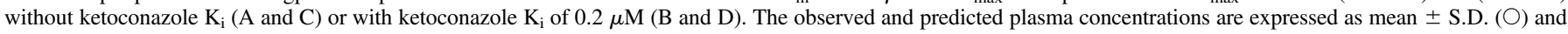
mean (-) with 5 th and 95 th percentiles (---), respectively.

main tiers: model development, verification, and application. Subsequently, it is critical to continuously verify and refine PBPK models, if necessary, on the basis of latest available data. Accordingly, we have refined the previously developed bosutinib PBPK model with the latest $\mathrm{F}_{\text {oral }}$ results. Apparently, the present PBPK model could rationalize the underlying DDI mechanisms with ketoconazole and rifampin through not only CYP3A4 but also P-gp. However, the present study undoubtedly highlighted the challenges of PBPK modeling for P-gp substrate drugs. Some potential issues raised in the present study therefore remain and warrant further discussion.

One of the most important pharmacokinetic parameters for oral drugs is $\mathrm{F}_{\text {oral }}\left(\mathrm{F}_{\mathrm{a}} \times \mathrm{F}_{\mathrm{g}} \times \mathrm{F}_{\mathrm{h}}\right)$. Bosutinib $\mathrm{F}_{\text {oral }}$ and $\mathrm{F}_{\mathrm{h}}$ were estimated at $\sim 0.3$ and $\sim 0.5$, respectively, in the $\mathrm{F}_{\text {oral }}$ study, and $\mathrm{F}_{\mathrm{a}}$ was estimated at $\sim 0.7$ in the mass-balance study at a dose of $500 \mathrm{mg}$. Subsequently, the calculated $\mathrm{F}_{\mathrm{g}}$ was $\sim 0.9$ from $\mathrm{F}_{\text {oral }}(\sim 0.3), \mathrm{F}_{\mathrm{a}}(\sim 0.7)$, and $\mathrm{F}_{\mathrm{h}}(\sim 0.5)$. Thus, the $\mathrm{F}_{\text {oral }}$ result was valuable in the verification of the PBPK models. However, the refined PBPK- $\mathrm{F}_{\mathrm{a}}$ models underpredicted the effects of ketoconazole and rifampin on bosutinib exposures. In both cases, the observed DDI results could not be recovered sufficiently by the model-predicted changes in bosutinib $F_{g}$ and $F_{h}$ as mentioned before, suggesting that bosutinib $\mathrm{F}_{\mathrm{a}}$ could possibly be altered by these precipitant drugs through P-gp-mediated efflux. Consistently, the increases in bosutinib exposures estimated as $\mathrm{C}_{\max }$ and $\mathrm{AUC}$ were supraproportional at the lower doses of
50-200 mg and approximately dose-proportional at the higher doses of 200-600 mg (http://www.accessdata.fda.gov/drugsatfda_docs/nda/2012/ 203341Orig1s000ClinPharmR.pdf). In contrast, the observed terminal half-lives (13-22 hours) were comparable across the doses, suggesting the linear elimination (e.g., hepatic clearance) across the doses tested. This finding appeared to be consistent with in vitro metabolism data showing much higher $\mathrm{K}_{\mathrm{m}}$ estimates of two major metabolites (8-23 $\mu \mathrm{M}$ for oxydechlorinated and $N$-desmethyl bosutinib) than the observed unbound steady-state $\mathrm{C}_{\max }$ of $\sim 0.03 \mu \mathrm{M}$ (http://www.accessdata.fda.gov/drugsatfda_docs/nda/2012/ 203341Orig1s000ClinPharmR.pdf). Thus, bosutinib nonlinear pharmacokinetics could possibly result from the dose-dependent increases in $F_{a}$ owing largely to a saturation of intestinal P-gp efflux.

Two of the most important factors governing $F_{a}$ are solubility and permeability, including active transports. It has been reported that it would be challenging to accurately predict the $\mathrm{F}_{\mathrm{a}}$ of many drugs, particularly basic compounds with low solubility (Zhang et al., 2014; Lin and Wong, 2017; Li et al., 2018). Bosutinib exhibits pH-dependent aqueous solubility, with the solubility decreasing from 21 to $0.038 \mathrm{mM}$ over the $\mathrm{pH}$ range of 1 to 6.8. In contrast, bosutinib intestinal concentrations calculated by dose amounts divided by $250 \mathrm{ml}$ were $0.38-3.8 \mathrm{mM}$ at doses of $50-500 \mathrm{mg}$. Therefore, bosutinib $\mathrm{F}_{\mathrm{a}}$ could be limited by solubility, whereas its distinctive $\mathrm{pH}$-dependent solubility could potentially increase its gastrointestinal solubility in vivo. Bosutinib exhibited positive food effects (high-fat meal) 

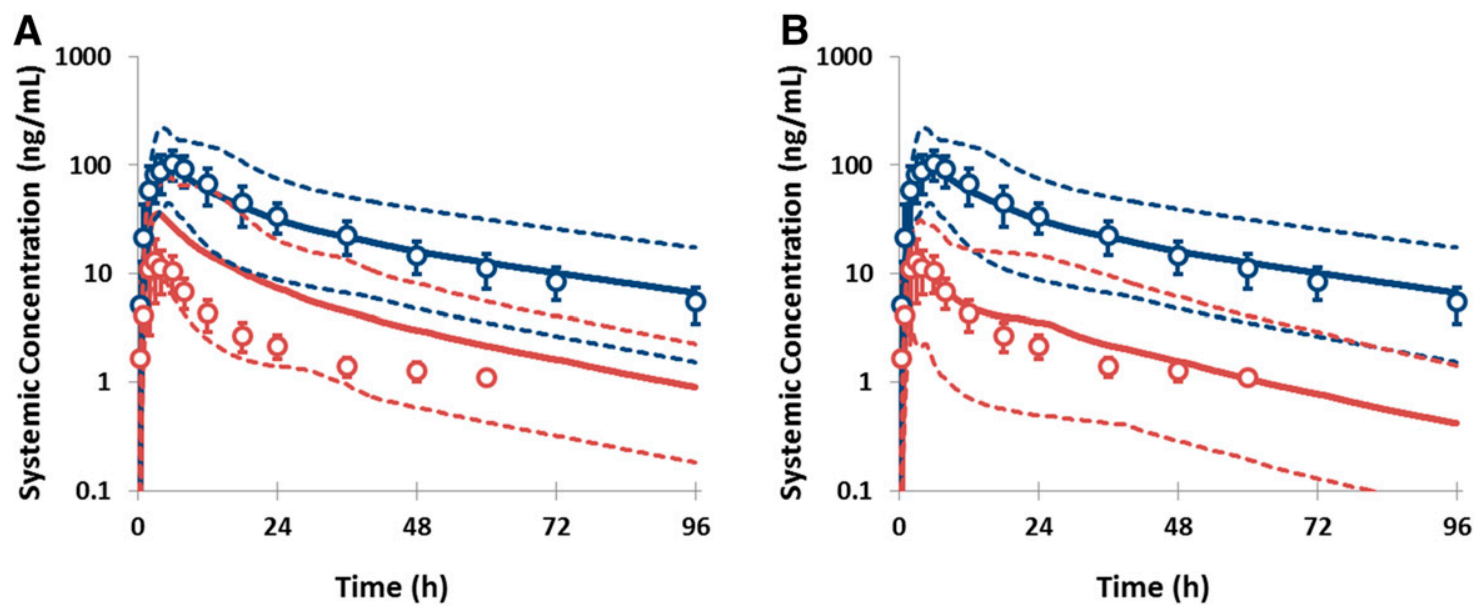

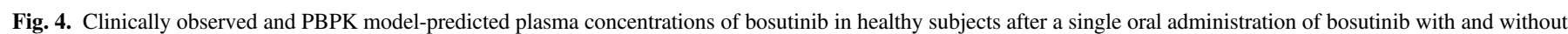

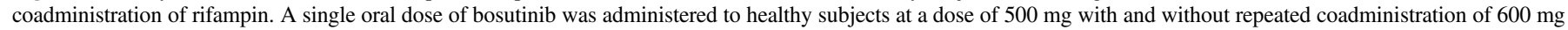

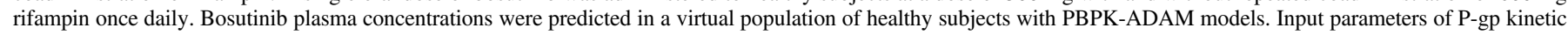

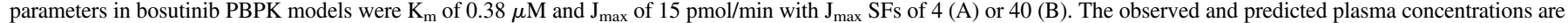
expressed as mean \pm S.D. $(\bigcirc)$ and mean $(-)$ with 5 th and 95 th percentiles (---), respectively.

on oral exposures $(\sim 1.6$-fold) in healthy volunteers $(n=23$ to 24$)$ at a dose of $400 \mathrm{mg}$ (http://www.accessdata.fda.gov/drugsatfda_docs/nda/2012/ 203341Orig1s000ClinPharmR.pdf). The observed positive food effects were sufficiently predicted by the present PBPK-ADAM model showing $\sim 1.5$-fold higher exposures in a fed state (high-fat meal) than a fasted state (Supplemental Table S2). Thus, the modeling results suggested that the PBPK-ADAM model could adequately predict the solubility-limited absorption. Bosutinib in vitro passive permeability was moderate $\left(\sim 7 \times 10^{-6} \mathrm{~cm} / \mathrm{s}\right)$, which was on the borderline of the proposed cut-off $\left(5 \times 10^{-6} \mathrm{~cm} / \mathrm{s}\right)$ for $\mathrm{F}_{\mathrm{a}}$ in the extended clearance classification system (Di et al., 2011; Varma et al., 2012). The relative P-gp distribution increases from proximal to distal small intestine, although expression levels appear slightly higher in jejunum than ileum (Fricker et al., 1996; Mouly and Paine, 2003; Englund et al., 2006; Harwood et al., 2015). Therefore, highly soluble and permeable drugs, even those that are P-gp substrates, can be absorbed rapidly and extensively in duodenum and proximal jejunum. In contrast, P-gpmediated efflux frequently reduces absorption rate and extent of P-gp substrates with low-to-moderate solubility or permeability. Consistent with this, bosutinib absorption was relatively slow, with the observed median $\mathrm{t}_{\max }$ of $4-6$ hours, and its $\mathrm{F}_{\mathrm{a}}$ was incomplete $(\leq 0.7)$ at the doses tested. Unbound intracellular enterocyte concentrations calculated by $\mathrm{k}_{\mathrm{a}}\left(0.61\right.$ hour $\left.^{-1}\right), \mathrm{F}_{\mathrm{a}}(1), \mathrm{f}_{\mathrm{u}, \text { gut }}(0.063)$, and enterocyte blood flow (18 1/h) were $0.2-2.0 \mu \mathrm{M}$ at a doses of 50-500 mg (Rostami-Hodjegan and Tucker, 2004). When the predicted $F_{a}$ values $(0.3-0.7)$ were used, the calculated unbound intracellular enterocyte concentrations were 0.06-1.4 $\mu \mathrm{M}$. In the ADAM model, bosutinib enterocyte concentrations were predicted in each region (subcompartment) of the gastrointestinal tract as a function of time. The predicted maximal concentrations in the subcompartments were $0.1-0.7$ and $0.8-2.4$ $\mu \mathrm{M}$ at doses of 100 and $500 \mathrm{mg}$, respectively. Thus, the predicted enterocyte concentrations were in a range comparable to the in vitro $\mathrm{K}_{\mathrm{m}}(0.38 \mu \mathrm{M})$. Collectively, these findings suggested a potential interplay between the $\mathrm{pH}$-dependent solubility, moderate permeability, and P-gp-mediated efflux on bosutinib absorption, as suggested also for other P-gp substrates (Burton et al., 2002; Jamei et al., 2009b; Sjogren et al., 2013).

SAO are powerful tools to assess the effects on overall outputs of uncertainty around input parameters, often leading to model improvement and additional mechanistic insights (Zhao et al., 2012; Shardlow et al., 2013; Shepard et al., 2015). Accordingly, the SAO for bosutinib P-gp kinetic parameters were performed in the present study. First,

TABLE 7

PBPK-ADAM model-predicted pharmacokinetic parameters of bosutinib in bosutinib 500-mg single-dose DDI studies with verapamil and itraconazole

Data are expressed as geometric mean with percent coefficient of variation (CV\%) except for $\mathrm{C}_{\max } \mathrm{R}$ and AUCR with $90 \%$ confidence interval in parentheses $(n=6$ per group $\times 6$ groups for the predicted).

\begin{tabular}{|c|c|c|c|c|c|c|c|}
\hline \multirow{2}{*}{ PBPK Model } & \multirow{2}{*}{ Precipitant Drug } & \multirow{2}{*}{ Group $^{a}$} & \multirow{2}{*}{$\frac{\mathrm{K}_{\mathrm{i}}^{b}}{\mu M}$} & \multirow{2}{*}{$\begin{array}{l}\mathrm{C}_{\max } \\
n g / m l\end{array}$} & \multirow{2}{*}{$\begin{array}{c}\text { AUC } \\
n g \cdot h / m l\end{array}$} & \multirow{2}{*}{$\begin{array}{c}\mathrm{C}_{\max } \mathrm{R}^{c} \\
\text { ratio }\end{array}$} & \multirow{2}{*}{$\begin{array}{c}\mathrm{AUCR}^{c} \\
\text { ratio }\end{array}$} \\
\hline & & & & & & & \\
\hline \multirow[t]{6}{*}{ ADAM } & Itraconazole & Control & - & $114(51)$ & 2578 (71) & - & - \\
\hline & & Test & - & $228(46)$ & $21,108(123)$ & $2.0(1.9-2.1)$ & $8.5(6.5-10)$ \\
\hline & & & 0.5 & $229(46)$ & $21,159(123)$ & $2.0(1.9-2.1)$ & $8.5(6.5-10)$ \\
\hline & Verapamil & Control & - & 112 (49) & 2528 (70) & - & - \\
\hline & & Test & - & $190(50)$ & $11,269(110)$ & $1.7(1.6-1.8)$ & $4.5(3.7-5.3)$ \\
\hline & & & 0.16 & $226(49)$ & $13,015(111)$ & $2.0(1.9-2.2)$ & $5.1(4.3-6.2)$ \\
\hline
\end{tabular}

- , not applicable.

${ }^{a}$ Bosutinib $500 \mathrm{mg}$ without and with itraconazole $200 \mathrm{mg}$ once daily (control and test groups, respectively) or verapamil $80 \mathrm{mg}$ three times a day.

${ }^{b} \mathrm{~K}_{\mathrm{i}}$ for intestinal P-gp.

${ }^{c}$ Ratios of $\mathrm{C}_{\max }$ and AUC in test group relative to control group. 
bosutinib $\mathrm{K}_{\mathrm{m}}$ was assumed to be intrinsic and was fixed. Consequently, $\mathrm{J}_{\max }$ SFs were optimized to adequately recover the observed results. The SAO suggested a dose-dependent decrease in P-gp-mediated $\mathrm{C}_{\text {Lint }}$ in intestine as a possible explanation for the dose-dependent decrease in SFs at the doses of 100 to $500 \mathrm{mg}$. The general hypothesis is that $\mathrm{J}_{\max }$ is consistent across doses. Thus, the difference in $\mathrm{J}_{\max }$ SFs between the doses suggested that $\mathrm{J}_{\max }$ SFs could be optimized as apparent $\mathrm{J}_{\max }$ instead of true $\mathrm{J}_{\max }$. One of the potential reasons could be that PBPK models might not adequately capture the interplay between P-gpmediated efflux, permeability, and $\mathrm{pH}$-dependent solubility in each region of gastrointestinal tract, e.g., the regional differences in P-gpmeditated $\mathrm{CL}_{\text {int }}$. Further model refinement may be required to recover nonlinear pharmacokinetics of bosutinib across doses, suggesting the present PBPK models could be considered to be "fit-for-purpose" models.

Ketoconazole is generally assumed to be an inhibitor only of CYP3A in clinical DDI studies, although ketoconazole is known to inhibit P-gp (Rautio et al., 2006; Vermeer et al., 2016). The reason behind it could probably be the minimal P-gp effects on the absorption of many dual CYP3A and P-gp substrates owing to the saturation of P-gp-mediated efflux at clinical doses. Clinically observed bosutinib $\mathrm{C}_{\max } \mathrm{R}$ and AUCR by ketoconazole was more pronounced at a dose of $100 \mathrm{mg}$ than $500 \mathrm{mg}$, which appeared to be consistent with the dose-dependent saturation of P-gp-mediated efflux (Tables 4 and 5). To adequately recover the observed DDIs, the SAO indicated a ketoconazole in vivo $\mathrm{K}_{\mathrm{i}}$ of $0.1-0.3 \mu \mathrm{M}$, which were in line with the lower end of the reported in vitro $\mathrm{IC}_{50}$ of $\sim 0.2 \mu \mathrm{M}$ in the DIDB. The $\mathrm{K}_{\mathrm{i}}$ values for itraconazole and verapamil used in the PBPK models were also near the lower end of reported values as noted above. Overall, the PBPK modeling results suggested minimal impact of P-gp-mediated efflux on bosutinib DDIs with P-gp inhibitors at the clinically recommended dose of $500 \mathrm{mg}$.

Rifampin is well known to be a modulator for not only cytochrome P450 enzymes but also transporter proteins, including P-gp (Haslam et al., 2008; Williamson et al., 2013; Wagner et al., 2016). Following multiple-dose coadministration of rifampin, oral exposures of a P-gp probe substrate, digoxin, decreased by $\sim 2$-fold, whereas intravenous exposures were not significantly altered (Novi et al., 1980; Gault et al., 1984; Greiner et al., 1999). Thus, the decrease in oral exposure of digoxin was probably owing to rifampin-mediated P-gp induction in intestine resulting in the decrease in digoxin $\mathrm{F}_{\mathrm{a}}$. Since bosutinib was a dual-substrate of CYP3A4 and P-gp, the decrease in bosutinib exposures by rifampin could possibly be caused by complex DDI mechanisms through not only CYP3A4 but also P-gp. Consistently, the effect of rifampin on bosutinib exposures was considerably underpredicted by the PBPK models when accounting for only rifampin-mediated CYP3A4 induction. The subsequent SAO suggested that the observed DDI results could adequately be recovered by 8 - to 12 -fold increases in intestinal P-gp abundances by rifampin (Table 6). The predicted fold-increases in intestinal P-gp abundances were comparable to the reported results (Giessmann et al., 2004). The predicted increases in P-gp abundances were also comparable to those in CYP3A4 induction (Almond et al., 2016), which appeared to be consistent with the literature reporting the similar increases in rifampin-mediated CYP3A4 and P-gp expression levels (Greiner et al., 1999). For DDI prediction with CYP3A inducers, efavirenz is frequently used for PBPK modeling as a moderate inducer (Ke et al., 2016; Wagner et al., 2016). However, it has been reported that efavirenz did not induce intestinal P-gp in the clinic (Mouly et al., 2002; Oswald et al., 2012). Provisionally, the results of bosutinib DDI prediction with rifampin, when the different fold-increases in intestinal P-gp abundance (i.e., 1- to 16-fold) are used, could possibly serve as indexes of DDI prediction with CYP3A/P-gp dual inducers (Supplemental Table S1). With P-gp abundances increasing by 16-fold, bosutinib $\mathrm{C}_{\max } \mathrm{R}$ and AUCR decreased from 0.34 to 0.09 and 0.21 to 0.06 , respectively, suggesting some degree of impact of intestinal P-gp induction on bosutinib exposures at the clinically recommended dose of $500 \mathrm{mg}$.

In summary, the present study demonstrated that bosutinib PBPK models are reasonably refined, as verified on the basis of currently available data. The results suggested that P-gp-mediated intestinal efflux could play a substantial role on bosutinib DDIs with ketoconazole and rifampin. Overall, it may prove critical to incorporate P-gp kinetics in the PBPK models in order to understand the underlying DDI mechanisms for P-gp substrates such as bosutinib, particularly when clinical data exhibit nonlinear pharmacokinetics that could be a result of saturation of intestinal P-gp-mediated efflux.

\section{Acknowledgments}

The authors thank Masoud Jamei, Shriram M. Pathak, and Matthew D. Harwood (Simcyp Ltd., Sheffield, United Kingdom) for valuable inputs on PBPK modeling. We also acknowledge former colleagues Seong H. Park and Aram Oganesian (Biotransformation \& Drug Metabolism, Pfizer, Collegeville, PA) for Caco-2 assay data and Poe-Hirr Hsyu (Clinical Pharmacology, Pfizer, San Diego, CA), Richat Abbas (Clinical Pharmacology, Pfizer Essential Health, Collegeville, PA), and Chiho Ono (Clinical Pharmacology, Pfizer Japan Inc, Tokyo, Japan) for valuable discussion about bosutinib pharmacokinetics.

\section{Authorship Contributions}

Participated in research design: Yamazaki.

Performed data analysis: Costales, Kimoto, Yamazaki.

Wrote or contributed to the writing of the manuscript: Costales, Kimoto, Loi, Varma, Yamazaki.

\section{References}

Abbas R, Boni J, and Sonnichsen D (2015) Effect of rifampin on the pharmacokinetics of bosutinib, a dual Src/Abl tyrosine kinase inhibitor, when administered concomitantly to healthy subjects. Drug Metab Pers Ther 30:57-63.

Abbas R, Chaudhary I, Hug BA, Leister C, Burns J, Vashishtha S, Erve JCL, and Sonnichsen D (2010) Mass balance, metabolic disposition, metabolite characterization, and pharmacokinetics of oral 14C-labeled bosutinib in healthy subjects. Drug Metab Rev 42:228-229.

Abbas R, Hug BA, Leister C, Burns J, and Sonnichsen D (2011) Effect of ketoconazole on the pharmacokinetics of oral bosutinib in healthy subjects. J Clin Pharmacol 51:1721-1727.

Abbas R, Hug BA, Leister C, and Sonnichsen D (2012) A randomized, crossover, placebo- and moxifloxacin-controlled study to evaluate the effects of bosutinib (SKI-606), a dual Src/Abl tyrosine kinase inhibitor, on cardiac repolarization in healthy adult subjects. Int $J$ Cancer 131: E304-E311.

Almond LM, Mukadam S, Gardner I, Okialda K, Wong S, Hatley O, Tay S, Rowland-Yeo K, Jamei M, Rostami-Hodjegan A, et al. (2016) Prediction of drug-drug interactions arising from CYP3A induction using a physiologically based dynamic model. Drug Metab Dispos 44: 821-832.

Burton PS, Goodwin JT, Vidmar TJ, and Amore BM (2002) Predicting drug absorption: how nature made it a difficult problem. $J$ Pharmacol Exp Ther 303:889-895.

Di Li, Whitney-Pickett C, Umland JP, Zhang H, Zhang X, Gebhard DF, Lai Y, Federico JJ, III, Davidson RE, Smith R, et al. (2011) Development of a new permeability assay using low-efflux MDCKII cells. J Pharm Sci 100:4974-4985.

Englund G, Rorsman F, Rönnblom A, Karlbom U, Lazorova L, Gråsjö J, Kindmark A, and Artursson P (2006) Regional levels of drug transporters along the human intestinal tract: co-expression of ABC and SLC transporters and comparison with Caco-2 cells. Eur J Pharm Sci 29:269-277.

Fricker G, Drewe J, Huwyler J, Gutmann H, and Beglinger C (1996) Relevance of p-glycoprotein for the enteral absorption of cyclosporin A: in vitro-in vivo correlation. Br J Pharmacol 118 : $1841-1847$.

Gault H, Longerich L, Dawe M, and Fine A (1984) Digoxin-rifampin interaction. Clin Pharmacol Ther 35:750-754

Giessmann T, Modess C, Hecker U, Zschiesche M, Dazert P, Kunert-Keil C, Warzok R, Engel G, Weitschies W, Cascorbi I, et al. (2004) CYP2D6 genotype and induction of intestinal drug transporters by rifampin predict presystemic clearance of carvedilol in healthy subjects. Clin Pharmacol Ther 75:213-222.

Greiner B, Eichelbaum M, Fritz P, Kreichgauer HP, von Richter O, Zundler J, and Kroemer HK (1999) The role of intestinal P-glycoprotein in the interaction of digoxin and rifampin. J Clin Invest 104:147-153.

Guest EJ, Aarons L, Houston JB, Rostami-Hodjegan A, and Galetin A (2011) Critique of the twofold measure of prediction success for ratios: application for the assessment of drug-drug interactions. Drug Metab Dispos 39:170-173.

Harwood MD, Achour B, Russell MR, Carlson GL, Warhurst G, and Rostami-Hodjegan A (2015) Application of an LC-MS/MS method for the simultaneous quantification of human intestinal transporter proteins absolute abundance using a QconCAT technique. J Pharm Biomed Anal 110:27-33.

Haslam IS, Jones K, Coleman T, and Simmons NL (2008) Rifampin and digoxin induction of MDR1 expression and function in human intestinal (T84) epithelial cells. Br J Pharmacol 154:246-255. 
Hsyu PH, Pignataro DS, and Matschke K (2017) Effect of aprepitant, a moderate CYP3A4 inhibitor, on bosutinib exposure in healthy subjects. Eur J Clin Pharmacol 73:49-56 .

Hsyu PH, Pignataro DS, and Matschke K (2018) Absolute Bioavailability of Bosutinib in Healthy Subjects From an Open-Label, Randomized, 2-Period Crossover Study. Clin Pharmacol Drug Dev 7:373-381.

Huang SM and Rowland M (2012) The role of physiologically based pharmacokinetic modeling in regulatory review. Clin Pharmacol Ther 91:542-549.

Jamei M, Marciniak S, Feng K, Barnett A, Tucker G, and Rostami-Hodjegan A (2009a) The Simcyp population-based ADME simulator. Expert Opin Drug Metab Toxicol 5:211-223.

Jamei M, Turner D, Yang J, Neuhoff S, Polak S, Rostami-Hodjegan A, and Tucker G (2009b) Population-based mechanistic prediction of oral drug absorption. AAPS J 11:225-237.

Jones HM, Chen Y, Gibson C, Heimbach T, Parrott N, Peters SA, Snoeys J, Upreti VV, Zheng M, and Hall SD (2015) Physiologically based pharmacokinetic modeling in drug discovery and development: a pharmaceutical industry perspective. Clin Pharmacol Ther 97:247-262.

Jones H and Rowland-Yeo K (2013) Basic concepts in physiologically based pharmacokinetic modeling in drug discovery and development. CPT Pharmacometrics Syst Pharmacol 2: 63 . Ke A, Barter Z, Rowland-Yeo K, and Almond L (2016) Towards a best practice approach in PBPK modeling: case example of developing a unified efavirenz model accounting for induction of CYPs 3A4 and 2B6. CPT Pharmacometrics Syst Pharmacol 5:367-376.

Koziolek M, Schneider F, Grimm M, Mode $\beta$ C, Seekamp A, Roustom T, Siegmund W, and Weitschies W (2015) Intragastric $\mathrm{pH}$ and pressure profiles after intake of the high-caloric, high-fat meal as used for food effect studies. J Control Release 220 (Pt A):71-78.

Lavé T, Parrott N, Grimm HP, Fleury A, and Reddy M (2007) Challenges and opportunities with modelling and simulation in drug discovery and drug development. Xenobiotica 37:1295-1310.

Li M, Zhao P, Pan Y, and Wagner C (2018) Predictive performance of physiologically based pharmacokinetic models for the effect of food on oral drug absorption: current status. CPT Pharmacometrics Syst Pharmacol 7:82-89.

Lin L and Wong H (2017) Predicting oral drug absorption: mini review on physiologically-based pharmacokinetic models. Pharmaceutics 9:41 DOI: doi: 10.3390/pharmaceutics9040041.

Mouly S, Lown KS, Kornhauser D, Joseph JL, Fiske WD, Benedek IH, and Watkins PB (2002) Hepatic but not intestinal CYP3A4 displays dose-dependent induction by efavirenz in humans. Clin Pharmacol Ther 72:1-9.

Mouly S and Paine MF (2003) P-glycoprotein increases from proximal to distal regions of human small intestine. Pharm Res 20:1595-1599.

Nestorov I (2007) Whole-body physiologically based pharmacokinetic models. Expert Opin Drug Metab Toxicol 3:235-249.

Novi C, Bissoli F, Simonati V, Volpini T, Baroli A, and Vignati G (1980) Rifampin and digoxin: possible drug interaction in a dialysis patient. JAMA 244:2521-2522.

Ono C, Hsyu PH, Abbas R, Loi CM, and Yamazaki S (2017) Application of physiologically based pharmacokinetic modeling to the understanding of bosutinib pharmacokinetics: prediction of drug-drug and drug-disease interactions. Drug Metab Dispos 45:390-398.

Oswald S, Meyer zu Schwabedissen HE, Nassif A, Modess C, Desta Z, Ogburn ET, Mostertz J, Keiser M, Jia J, Hubeny A, et al. (2012) Impact of efavirenz on intestinal metabolism and transport: insights from an interaction study with ezetimibe in healthy volunteers. Clin Pharmacol Ther 91:506-513.

Prueksaritanont T, Chu X, Gibson C, Cui D, Yee KL, Ballard J, Cabalu T, and Hochman J (2013) Drugdrug interaction studies: regulatory guidance and an industry perspective. AAPS J 15:629-645.

Rautio J, Humphreys JE, Webster LO, Balakrishnan A, Keogh JP, Kunta JR, Serabjit-Singh CJ, and Polli JW (2006) In vitro p-glycoprotein inhibition assays for assessment of clinical drug interaction potential of new drug candidates: a recommendation for probe substrates. Drug Metab Dispos 34:786-792.

Rodgers T, Leahy D, and Rowland M (2005) Physiologically based pharmacokinetic modeling 1: predicting the tissue distribution of moderate-to-strong bases. J Pharm Sci 94:1259-1276.

Rostami-Hodjegan A and Tucker G (2004) 'In silico' simulations to assess the 'in vivo' consequences of 'in vitro' metabolic drug-drug interactions. Drug Discov Today Technol 1:441-448.
Rowland M, Peck C, and Tucker G (2011) Physiologically-based pharmacokinetics in drug development and regulatory science. Annu Rev Pharmacol Toxicol 51:45-73.

Sager JE, Yu J, Ragueneau-Majlessi I, and Isoherranen N (2015) Physiologically based pharmacokinetic (PBPK) modeling and simulation approaches: a systematic review of published models, applications, and model verification. Drug Metab Dispos 43:1823-1837.

Shardlow CE, Generaux GT, Patel AH, Tai G, Tran T, and Bloomer JC (2013) Impact of physiologically based pharmacokinetic modeling and simulation in drug development. Drug Metab Dispos 41:1994-2003.

Shebley M, Sandhu P, Emami Riedmaier A, Jamei M, Narayanan R, Patel A, Peters SA, Reddy VP, Zheng M, de Zwart L, et al. (2018) Physiologically based pharmacokinetic model qualification and reporting procedures for regulatory submissions: a consortium perspective. Clin Pharmacol Ther DOI: $10.1002 /$ cpt.1013 [published ahead of print]

Shepard T, Scott G, Cole S, Nordmark A, and Bouzom F (2015) Physiologically based models in regulatory submissions: output from the ABPI/MHRA forum on physiologically based modeling and simulation. CPT Pharmacometrics Syst Pharmacol 4:221-225.

Sjögren E, Westergren J, Grant I, Hanisch G, Lindfors L, Lennernäs H, Abrahamsson B, and Tannergren C (2013) In silico predictions of gastrointestinal drug absorption in pharmaceutical product development: application of the mechanistic absorption model GI-Sim. Eur J Pharm Sci 49:679-698.

Syed YY, McCormack PL, and Plosker GL (2014) Bosutinib: a review of its use in patients with Philadelphia chromosome-positive chronic myelogenous leukemia. BioDrugs 28:107-120.

Tachibana T, Kitamura S, Kato M, Mitsui T, Shirasaka Y, Yamashita S, and Sugiyama Y (2010) Model analysis of the concentration-dependent permeability of P-gp substrates. Pharm Res 27:442-446.

Varma MV, Gardner I, Steyn SJ, Nkansah P, Rotter CJ, Whitney-Pickett C, Zhang H, Di L, Cram M, Fenner KS, et al. (2012) pH-Dependent solubility and permeability criteria for provisional biopharmaceutics classification (BCS and BDDCS) in early drug discovery. Mol Pharm 9:1199-1212.

Vermeer LM, Isringhausen CD, Ogilvie BW, and Buckley DB (2016) Evaluation of ketoconazole and its alternative clinical CYP3A4/5 inhibitors as inhibitors of drug transporters: the in vitro effects of ketoconazole, ritonavir, clarithromycin, and itraconazole on 13 clinically-relevant drug transporters. Drug Metab Dispos 44:453-459.

Wagner C, Pan Y, Hsu V, Grillo JA, Zhang L, Reynolds KS, Sinha V, and Zhao P (2015) Predicting the effect of cytochrome P450 inhibitors on substrate drugs: analysis of physiologically based pharmacokinetic modeling submissions to the US Food and Drug Administration. Clin Pharmacokinet 54:117-127.

Wagner C, Pan Y, Hsu V, Sinha V, and Zhao P (2016) Predicting the effect of CYP3A inducers on the pharmacokinetics of substrate drugs using physiologically based pharmacokinetic (PBPK) modeling: an analysis of PBPK submissions to the US FDA. Clin Pharmacokinet 55:475-483.

Williamson B, Dooley KE, Zhang Y, Back DJ, and Owen A (2013) Induction of influx and efflux transporters and cytochrome P450 3A4 in primary human hepatocytes by rifampin, rifabutin, and rifapentine. Antimicrob Agents Chemother 57:6366-6369.

Zhang H, Xia B, Sheng J, Heimbach T, Lin TH, He H, Wang Y, Novick S, and Comfort A (2014) Application of physiologically based absorption modeling to formulation development of a low solubility, low permeability weak base: mechanistic investigation of food effect. AAPS PharmSciTech 15:400-406.

Zhao P, Rowland M, and Huang SM (2012) Best practice in the use of physiologically based pharmacokinetic modeling and simulation to address clinical pharmacology regulatory questions. Clin Pharmacol Ther 92:17-20.

Address correspondence to: Dr. Shinji Yamazaki, Pharmacokinetics, Dynamics and Metabolism, La Jolla Laboratories, Pfizer Worldwide Research and Development, 10777 Science Center Drive, San Diego, CA 92121. E-mail: shinji.yamazaki@ pfizer.com 